ORNL/TM-11471

OAK RIDGE

NATIONAL

LABORATORY

MARTIN MARIETIA
Nov 1.51991

\section{Aluminum Nitrate Recrystallization and Recovery from Liquid Extraction Raffinates}

W. L. Griffith

A. L. Compere

J. M. Googin

W. P. Huxtable

\section{MANAGED BY}

MARTIN MARIETTA ENERGY SYSTEMS, INC.

FOR THE JNITEO STATES

DEPARTMENT OF ENERGY 
This report has been reproduced directly from the best available copy.

Available to DOE and DOE contractors from the Otfice of Scientific and Technical Information, P.O. Box 62, Oak Ridge, TN 37831; prices available from (615) 576-8401, FTS 626-8401.

Available to the public from the National Technical Information Service, U.S. Departinent of Commerce, 5285 Port Royal Rd., Springfield, VA 22161.

This report was prepared as an account of work sponsored by an agency of the United States Government. Neither the United States Government nor any agency thereof, nor any of their employees, makes any warranty, express or implied, or assumes any legal liability or responsibility for the accuracy, completeness, or usefulness of any information, apparatus, product, or process disclosed, or represents that its use would not infringe privately owned rights. Reference herein to any specific comrnercial product, process, or service by trade name, trademark, manufacturer, or otherwise, does not necessarily constitute or imply its endorsement, recommendation, or favoring by the United States Government or any agency thereof. The views and opinions of authors expressed herein do not necessarily state or reflect those of the United States Government or any agency thereof. 


\title{
Aluminum Nitrate Recrystallization and Recovery from Liquid Extraction Raffinates
}

\author{
W. L. Griffith \\ A. L. Compere \\ J. M. Googin \\ W. P. Huxtable
}

Date Published: September 1991

Prepared by the Oak Ridge National Laboratory

Oak Ridge, Tennessee 37831

managed by

Martin Marietta Energy Systems, Inc.

for the

U. S. Department of Energy

under Contract No. DE-AC05-840R21400
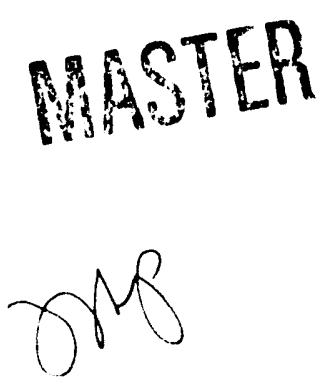


\section{Contents}

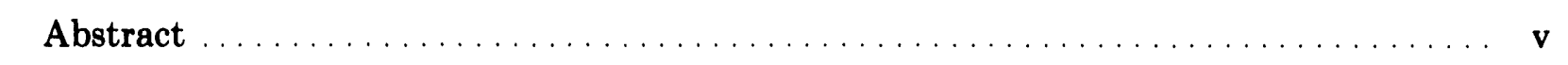

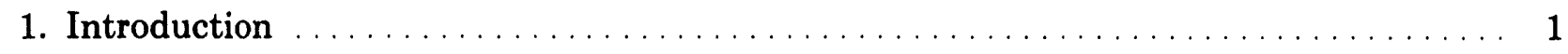

2. Experimental Plan $\ldots \ldots \ldots \ldots \ldots \ldots \ldots \ldots \ldots \ldots \ldots \ldots \ldots \ldots \ldots \ldots \ldots \ldots$

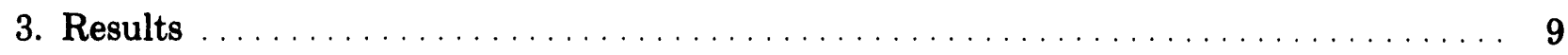

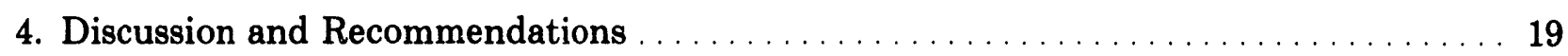

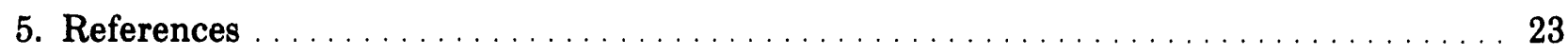

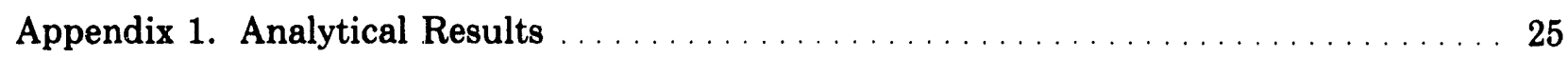

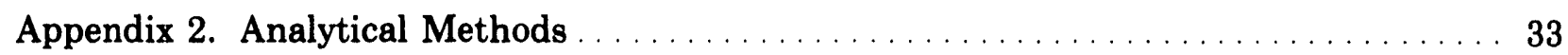




\begin{abstract}
The solid sludges resulting from biodenitrification of discarded aluminum nitrate are the largest Y-12 Plant process solid waste. Aluminum nitrate feedstocks also represent a major plant materials cost. The chemical constraints on aluminum nitrate recycle were investigated to determine the feasibility of increasing recycle while maintaining acceptable aluminum nitrate purity. Reported phase behavior of analogous systems, together with bench research, indicated that it would be possible to raise the recycle rate from $35 \%$ to between 70 and $90 \%$ by successive concentration and recrystallization of the mother liquor. A full scale pilot test successfully confirmed the ability to obtain $70 \%$ recycle in existing process equipment.

This work indicates the possibility of increasing recycle rates above $70 \%$. Fluoride accumulation is expected to place an upper limit on aluminum nitrate recycle. Better control and removal of fluorides, as both insoluble tank precipitates and free fluorides, is needed to hold corrosion to acceptable levels. Minimizing the introduction of fluorides into the recycle system is, of course, the most effective method of fluoride control.

Analysis of the concentrations of the process streams indicated that valence I and II cations did not concentrate in the aluminum nitrate crystals. However, valence III cations, which are similar to aluminum in chemical behavior, were less well separated. Methods for selectively concentrating and removing these materials will be needed at very high aluminum nitrate recovery rates. Modification of the centrifuge system to provide separate collection of crystal wash streams can decrease accumulation of valence III cation contaminants. Changes in the extraction process producing acidic aluminum nitrate raffinates could decrease two historic problems, accumulation of oxalate precipitates (a carbitol degradation product) and any organics contributing to surface fouling. Standard methods for formally collecting and evaluating results on product quality could form the basis for the EVOPS, or evolutionary operating process standards, procedure needed to permit maximum recycle without loss of product quality during the implementation of planned process changes.
\end{abstract}




\section{Introduction}

This report presents the results of a study directed toward increasing the amount of $\mathrm{Al}\left(\mathrm{NO}_{3}\right)_{3} \cdot 9 \mathrm{H}_{2} \mathrm{O}$ recycled by the $\mathrm{Y}-12$ Plant. The $\mathrm{Al}\left(\mathrm{NO}_{3}\right)_{3} \cdot 9 \mathrm{H}_{2} \mathrm{O}$ is biodenitrified to produce the largest $\mathrm{Y}-12$ Plant process solid waste. In addition to simple chemical replacement savings, a substantial increase in $\mathrm{Al}\left(\mathrm{NO}_{3}\right)_{3} \cdot 9 \mathrm{H}_{2} \mathrm{O}$ recycle could provide a substantial increase in the life of present landfill facilities and decreases in process manpower, chemical consumption, and waste disposal costs. If $\mathrm{Al}\left(\mathrm{NO}_{3}\right)_{3} \cdot 9 \mathrm{H}_{2} \mathrm{O}$ recycle could be doubled, it might also be possible to eliminate the biodenitrification process. This would further decrease manpower, disposal, and purchased carbon source costs. Because this project is directed toward cost and waste reduction, major emphasis has been placed on the manipulation of process chemistry. The need for new process equipment has been minimized. In addition to reducing the cost associated with process changes, this strategy has permitted pilot testing at the end of a recovery campaign in existing process equipment and has also made it possible to institute process improvements promptly.

Because the major emphasis of this study was effective manipulation of process chemistry to provide increased recycle, the literature concerning recovery of raffinates and similar solutions was surveyed. Most extraction processes for recovering uranium from solution or purifying uranium involve separations from solutions which contain substantial amounts of both nitric acid and one or more concentrated nitrate salts. Across the last half century, a variety of different chemical systems have been used to accommodate various uranium separation needs (Patton and coworkers, 1963). To increase the efficiency of uranium extraction from nitric acid solution, a variety of salting agents, including aluminum, magnesium, sodium, calcium, copper, and ammonium nitrates, have been used successfully. However, aluminum nitrate has been successfully used as a salting agent for over four decades and remains the salting agent of choice at present because of its ability to complex fluorides. This provides adequate corrosion protection for steel and glass process equipment.

The process used has gradually evolved to meet the changing needs of the nuclear enterprise. Aluminum mono- and difluoride nitrate complexes were used in the 1940's to process uranium hexafluoride solutions. As described by Mesmer and Rutenberg (1973) boron is also an effective fluoride complexing agent. Its use as an aluminum replacement was also considered. The high concentrations of nitrate salts have also been used to facilitate the distillation of free nitric acid from solution by increasing its vapor pressure. Distillation of nitric acid from evaporator condensate has been pursued for three decades, although there have been a variety of process difficulties, including an explosion in a still (carbitol degradation product accumulation) and corrosion (acetic and hydrochloric acid accumulation).

Present interest in process changes is motivated by a desire to increase recycle and to decrease the amount of materials discharged to the environment. This has been a historic concern, and process changes to meet existing environmental standards have been addressed during process evolutionary changes (Union Carbide Corporation - Nuclear Division 1974). The cost of disposal has steadily increased to dominate process economics. The present 
level of recycle is relatively low, offering a perceived opportunity to decrease process costs. Improving the recovery of aluminum nitrate in the present nitrate recovery facility without changing existing equipment or aversely affecting facility operation were goals for this project.

\section{Equilibria of Concentrated Nitrates and Nitric Acid}

The chemistry of nitric acid - metal nitrate streams used in uranium processing is complex. Fortunately, the phase behavior of the systems involved tends to facilitate the production of aluminum nitrate of acceptable process quality. However, a brief review of the various facets of the aluminum nitrate - nitric acid system will indicate the complexity of the process interactions.

Nitric acid distillation pilot. As reported by Laggis (1974b), the Y-12 Plant has been interested in recovering nitric acid and metal nitrates for several decades.

Environmental problems were the major reason for the development of nitric acid recycle processes. Although Laggis was primarily concerned with development of effective corrosion control methods, he did review the history of nitrate and nitric acid recycle at Y-12 and other uranium facilities.

Nitric acid distillation facility. The pilot study was subsequently extended to provide a design basis for and guide to the operation of the Y-12 Nitrate Recycle Facility (Laggis 1974a). Based on calculations, Laggis estimated the maximum capacity and provided a complete flow and mass balance for each unit operation in the nitrate recycle facility. The values provided indicate that the facility is presently operating well below both design capacity and intended aluminum recycle.

Nitric acid recovery by evaporation and distillation. Arnold and coworkers (1956) of the Fernald Plant discussed the recovery of nitric acid from the raffinate solutions used to extract uranium, hafnium, zirconium, and thorium. These solutions generally contain a low concentration of free acid. Arnold and coworkers studied the use of a forced circulation flash evaporator to concentrate raffinate for recycle combined with vacuum distillation of vapors recovered from evaporation. A twelve plate bubble cap stainless steel distillation tower was used for nitric acid distillation.

Efimov and coworkers (1962) investigated the influence of aluminum, iron, magnesium, copper, sodium, and ammonium nitrates on the composition of the vapor phase above nitric acid solutions at atmospheric pressure. The work was directed toward understanding the effect of metal nitrates on the distillation of $\mathrm{HNO}_{3}$ from high nitrate waste solutions during evaporation. The investigators showed that the addition of metal nitrates increased both the boiling point and the concentration of the nitric acid in the vapor. As might be expected, the nitric acid tended to force salt crystallization. Efimov and coworkers developed equations correlating the concentrations of all three phases.

Dietrich (1973) detailed the distillative separation of nitric acid from aluminum nitrate raffinate streams. Using a boiling fluoride trap in the distillation column, it was possible to reduce the fluoride concentrations from 200 or $300 \mathrm{ppm}$ to less than one ppm. Average concentrations of fluoride were $18-37 \mathrm{ppm}$. During the recovery of $90 \%$ of nitric acid concentrations as high as $14 M$ were produced from 1 to $6 M$ nitric acid. 
Magnesium nitrate solubility as a function of calcium nitrate and nitric acid concentrations. Miniovich and coworkers (1975) determined solubility isotherms for magnesium nitrate and mixtures of calcium and magnesium nitrate in nitric acid. The results were plotted as functions of temperature and salt concentration.

Salt effects on vapor-liquid equilibria for the nitric acid-water system. Takeshi and coworkers (1985) presented vapor-liquid equilibria for nitric acid-water systems at $101.3 \mathrm{kPa}$ as a function of the concentration of calcium and magnesium nitrate salts. The concentration of nitric acid in the nitric-acid water azeotropic mixture decreased linearly with increasing salt concentrations. Magnesium nitrate evinced a greater salting out effect than did calcium nitrate.

Concentration of acidic nitrate solutions. Shakhova and coworkers (1979) reported that increasing acidity decreased precipitation of $\mathrm{Fe}(\mathrm{OH})_{3}$ in solutions of aluminum nitrate during nitric acid distillation.

Effect of increased crystallization temperature on crystal purity. Danilova and coworkers (1981) found that high purity aluminum nitrate could be obtained by crystallization from solutions with up to $2 \mathrm{mg} / \mathrm{g}$ of alkali metal as oxide.

Aluminum nitrate nonahydrate crystallization miniplant. The Bureau of Mines studied the production of alumina by $\mathrm{HNO}_{3}$ extraction of kaolinitic clay. Decreased $\mathrm{Al}\left(\mathrm{NO}_{3}\right)_{3} \cdot 9 \mathrm{H}_{2} \mathrm{O}$ quality as a function of impurity concentration and operation methods during continuous crystallization in a pilot unit was investigated (Turner and Rogers 1983). Based on their results, recrystallization can decrease most contaminants to acceptable levels. Valence three oxides, mainly iron and chromium oxides in clays, however, nore of concern as their solution behavior could be expected to follow patterns similar to those of aluminum. Crystal washing during centrifugation was an effective method for increasing crystal purity. Because the process arrangements used by the Bureau of Mines and by $\mathrm{Y}-12$ are similar, material balances for $\mathrm{Al}\left(\mathrm{NO}_{3}\right)_{3} \cdot 9 \mathrm{H}_{2} \mathrm{O}$ production were useful in preparing the engineering estimates included in this report. However, the higher levels of most process contaminants encountered during raffinate concentration and recycle provide a more challenging test case.

Saslawsky and coworkers (1935a and b) studied the phase behavior of ternary and quarternary systems of alkali metal nitrates, nitric acid, and water at temperatures ranging between 0 and $60^{\circ} \mathrm{C}$. As with the aluminum nitrate systems detailed by later investigators, the major precipitated phase was generally the nitrate salt of the predominant alkali. Mixed nitrates occurred only near the invariant point.

Godfrey (1964) described a counter-current crystallization process for purifying and recovering $\mathrm{Al}\left(\mathrm{NO}_{3}\right)_{3} \cdot 9 \mathrm{H}_{2} \mathrm{O}$ from the aqueous portion of extraction streams. The process was developed to meet Hanford remote operation requirements. A computer model of the system was developed and verified using one stage bench crystallization equipment. Based on mechanical considerations, $\mathrm{HNO}_{3}$ concentration was set at $57 \%$ and $\mathrm{Al}\left(\mathrm{NO}_{3}, 15 \%\right.$. At each $s$ age, the acid aluminum nitrate solution was heated to form a single phase liquid and cooled to precipitate equilibrium crystals. The mother liquor is used as a wash solution for the crystals in a more contaminated stage, while clean wash solution is supplied to the head of the cascade. The product is removed as a liquid acid nitrate solution for recycle to extraction, and the contaminants as a nitric acid solution. 
Godfrey and Benham (1964) presented a simulation of the previously described counter current crystallization process. In developing the process simulation model, a number of process assumptions were made. These include equal volumes and concentrations for all stages maintained by an appropriate tirst stage feed rate, overflow rates for each vessel constant and equal to the feed rate, and perfect mixing in each stage. The model assumptions were translated into a form suitable for use on iterative analog computers.

\section{Fluoride Complexes}

Fluoride is the most important impurity in aluminum nitrate- nitric acid systems because of the high corrosive potential of uncomplexed fluoride. To protect stainless steel and glass process equipment, aluminum is used to complex free fluoride. Although there are a variety of effective fluoride complexing agents, aluminum has worked well for over 40 years (Patton and coworkers 1963).

Solution stability of aluminum fluoride complexes. Tannanaev and Vinogradova investigated the stability of complexes formed between fluorine and multivalent cations (1957). They found that $\mathrm{AlF}_{2}{ }^{+}$ions were readily formed during dissolution of $\mathrm{CaF}_{3}$ salts in $\mathrm{Al}\left(\mathrm{NO}_{3}\right)_{3}$ solutions and in mixed $\mathrm{Al}\left(\mathrm{NO}_{3}\right)_{3}-\mathrm{Ca}\left(\mathrm{NO}_{3}\right)_{2}$ solutions. Increasing temperature increased the rate of aluminum fluoride complex formation. The complexes formed by aluminum salts, particularly nitrates, and fluoride, showed a gradual shift between the anion species, giving a relatively smooth transition from $\mathrm{Al}\left(\mathrm{NO}_{3}\right)_{3}$ through mixed salts, e. g.., $\mathrm{AlF}_{2} \mathrm{NO}_{3}$, to $\mathrm{AlF}_{3}$. This research indicated that high concentrations of aluminum provided a method for complexing fluoride so as to decrease corrosion of process equipment by fluoride-containing raffinate solutions.

Aluminum fluoride ion complexes in aqueous solutions. Matwiyoff and Wageman (1970) derived concentration equilibrium quotients, $Q_{n}$, for the hydrolysis of aluminum fluoride based on ${ }^{19} \mathrm{~F}$ nuclear magnetic resonance (NMR) signals as follows:

$$
\begin{array}{ll}
2 \mathrm{AlF}(\mathrm{aq})^{2+} \rightleftarrows \mathrm{Al}_{\mathrm{aq}}{ }^{3+}+\mathrm{AlF}_{2}^{+} & \mathrm{Q}_{1}=0.15 \\
2 \mathrm{AlF}_{2}(\mathrm{aq})^{+} \rightleftarrows \mathrm{AlF}_{3}(\mathrm{aq})+\mathrm{AlF}^{2+} & \mathrm{Q}_{2}=0.14 \\
2 \mathrm{AlF}_{3}(\mathrm{aq}) \rightleftarrows \mathrm{AlF}_{4}(\mathrm{aq})^{-}+\mathrm{AlF}_{2}{ }^{+} & \mathrm{Q}_{3}=0.038
\end{array}
$$

These values were consistent with those obtained from ${ }^{1} \mathrm{H}$ NMR signais.

For process mass balance calculations, we have found a similar treatment by Yamazaki and coworkers (1967) more convenient in that all equilibria were in terms of free fluoride ion. The values obtained were as follows:

$$
\begin{array}{ll}
\mathrm{Al}^{3+}+\mathrm{F}^{-} \rightleftarrows \mathrm{AlF}^{2+} & \mathbf{Q}_{1}=1.35 \times 10^{6} \\
\mathrm{AlF}^{2+}+\mathrm{F}^{-} \rightleftarrows \mathrm{AlF}_{2}^{+} & \mathbf{Q}_{2}=1.05 \times 10^{5} \\
\mathrm{AlF}_{2}^{+}+\mathrm{F}^{-} \rightleftarrows \mathrm{AlF}_{3} & \mathbf{Q}_{3}=7.1 \times 10^{3}
\end{array}
$$




$$
\begin{array}{ll}
\mathrm{AlF}_{3}+\mathrm{F}^{-} \rightleftarrows \mathrm{AlF}_{4}^{-} & \mathbf{Q}_{4}=5.5 \times 10^{2} \\
\mathrm{AlF}_{4}^{-}+\mathrm{F}^{-} \rightleftarrows \mathrm{AlF}_{5}^{2-} & \mathbf{Q}_{5}=43 \\
\mathrm{AlF}_{5}{ }^{2-}+\mathrm{F}^{-} \rightleftarrows \mathrm{AlF}_{6}{ }^{3-} & \mathbf{Q}_{6}=3 .
\end{array}
$$

The data and equilibria from both Matwiyoff and Wageman and from Yamazaki and coworkers was found to give consistent results. Mass equilibria derived using these data are presented in Chapter 4.

Aluminum fluoride complexes in aqueous fluorosilicic acid solutions. Buslaev and Petrosyants investigated the species present in hydrolyzed aluminum solutions containing fluorosilicic acid (1979). The full range of aluminum fluoride complexes, together with the aquo cation and silicon fluoride complexes containing 3 to 6 fluorines per silicon were simultaneously present in the solutions as determined by NMR spectrometry. In aluminum nitrate solutions, fluoroaluminate complezes predominate.

\section{Implications for Experimental Design}

Recycle is limited by the ability to recover acceptably pure aluminum nitrate nonahydrate crystals. Bench studies indicated that the bulk of impurities could be removed by separating residual mother liquor from crystals. At bench scale, this was accomplished by simply filtering and washing the crystals. In the pilot, centrifugation is used to separate the crystals.

Calcium, lithium, and magnesium impurities are high in raffinates. The phase studies reviewed show that aluminum nitrate crystals will predominate as long as aluminum is the major solution cation. Mixed nitrate crystals are likely to be formed near the invariant point. We have inferred that, even though process solution chemistry is substantially more complex than that of a simple ternary system, it is likely that spent mother liquor can be recycled by mixing it into the raffinate tank and reevaporating it. Aluminum nitrate is expected to predominate at recycle levels of $70 \%$ or more, depending on the concentration of other alkali cations.

The major process difficulties at high levels of recycle are expected to come fr $\mathrm{m}$ concentration of trivalent cations, such as chromium and iron, which could coprecipitate with aluminum in nitrate crystals. Selective stripping of trivalent cations other than aluminum is necessary and will be addressed in later studies. 


\section{Experimental Plan}

Aluminum nitrate is used as a complexing agent for fluorides in uranium extraction raffinates. At present, aluminum nitrate is made by reacting aluminum oxide with nitric acid. One-third to two-fifths of the material used is supplied by recycle. With increases in chemical purchase and disposal costs, increased recycle has become economically and environmentally attractive. The twin needs of limiting stainless steel corrosion by minimizing fluoride levels and maximizing aluminum nitrate purity and recycle by limiting cationic impurities constrain aluminum nitrate recycle. These constraints have created a need to explore the practical process limits on aluminum nitrate purity imposed by the physical chemistry of the complex raffinate salts mixture and by fluoride additions.

At present, a small fraction of process aluminum nitrate is recycled using the multistep process shown in Fig. 2.1. First is evaporation of aluminum nitrate - nitric acid raffinate which removes much of the nitric acid in the vapor, leaving a concentrated salt solution. This is followed by recovery of nitric acid by distillation from evaporator condensate. Aluminum nitrate as the nonahydrate is crystallized from the concentrated salts solution. Nitrate recycle thus involves both nitric acid and the nitrate salt. Spent liquor containing the impurities from crystallization is sent to biodenitrification.

The installed system was based on pilot research conducted by Struthers (Johnson 1973) and current system operation generally follows their recommendations (Struthers Scientific and International Corporation 1974). Concurrent with the aluminum nitrate crystallization efforts, nitric acid distillation from condensate underwent pilot testing, resulting in the installation of a nitric acid recycle system (Laggis 1974a,b). Although the current aluminum nitrate - nitric acid system has presented few operating problems since its installation, closure of the S-3 ponds, which provided ultimate disposal for process solids, has prompted consideration of process schemes providing increased recycle.

Raffinate is collected in the F-621 feed tank and flows from there to the F-624A evaporator and F-624 crystallizer. After crystallization, the product is centrifuged and the spent mother liquor is collected in tank F-630. Product $\mathrm{Al}\left(\mathrm{NO}_{3}\right)_{3} \cdot 9 \mathrm{H}_{2} \mathrm{C}$ crystals, together with a small amount of water used to facilitate crystal removal from the centrifuge, fall into the F-637 product tank. With at most minor physical problems, the process has operated satisfactorily for years.

Spent mother liquor is sent to biodenitrification. In biodenitrification, microorganisms ferment nitrate and an organic carbon source to form ritrogen and carbon dioxide gases with a consequent increase in $\mathrm{pH}$ of the solution. By the end of bioprocessing, aluminum hydroxide and calcium carbonate are precipitated, together with any residual biomass, heavy metals, and fluorides. This material is sent to the West End Treatment Facility for storage and ultimate disposal.

In September 1989, a pilot test of the proposed aluminum nitrate recycle using modified conventional equipment was arranged. Feasibility of proposed recycle levels, process arrangements, and operating parameters was assessed. Based on earlier bench tests it appeared that more nearly complete recycle of process aluminum as nitrate at acceptable purity was possible with existing equipment. It appeared possible to pilot test aluminum nitrate recycle by simply retaining, reconcentrating, and successively recrystallizing spent 
ORNL.DWF $91 \mathrm{M} 14676$

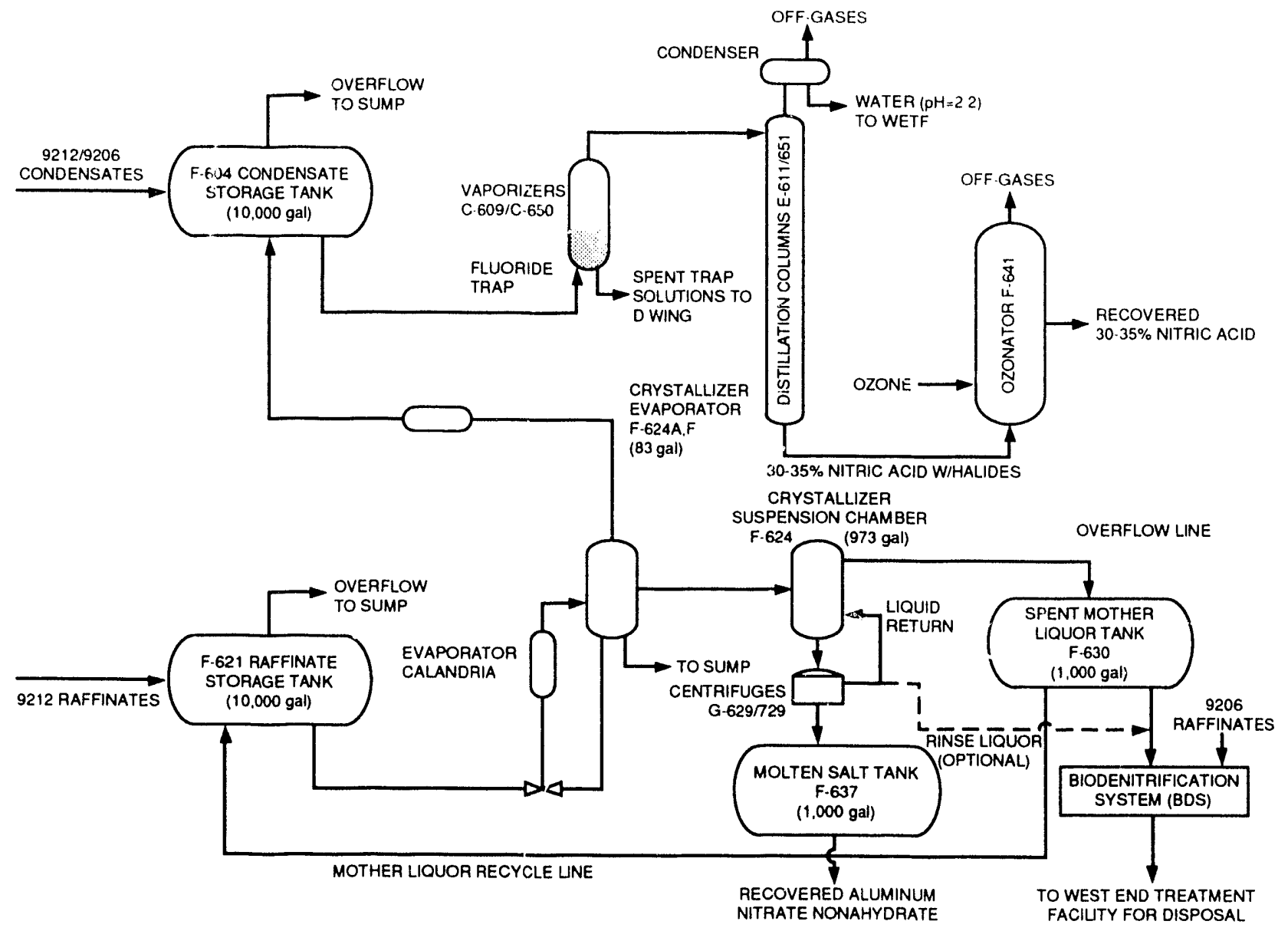

Fig. 2.1. Aluminum nitrate recovery facility process arrangement.

mother liquor. This test had the advantages of low cost, ease of performance, and use of the actual planned process equipment.

This project was originally undertaken in the hopes of raising the level of aluminum recycle to between three-fifths and two-thirds. This level could provide significant decreases in process waste, reductions in the cost of organic feedstocks to biodenitrification, and decreases in the purchase of aluminum compounds. This would permit phase-out of portions of the biodenitrification process. The question was how to structure pilot tests to give adequate information with minimal cost and effort.

After discussions with the operating staff, an alternative pilot test process schematic shown was developed. It diverts spent mother liquor back to the feed tarik for reconcentration and recrystallization. Although bench tests indicated the desirability of separating crystallization wash liquors from product, this could not be arranged during this series of pilot tests.

Samples were taken several times during the pilot run. The values report $\mathrm{d}$ reflect tank analysis for those time periods. However, additional feed was introduced into the feed tank during the pilot run. This changed the feed composition with time, and compositions may reflect process holdup. 


\section{Results}

The effect of aluminum nitrate recycle was tested at a pilot scale by piping spent mother liquor from the crystal recovery centrifuge back to the raifinate accumulation tank. The spent mother liquor was then successively reconcentrated and recrystallized using conventional process equipment following standard procedure. Although the pilot results should provide a good basis for process estimation, the success of the pilot run was limited by two omissions. First, crystal washing has been demonstrated to provide increased product purity by removing spent mother liquor contaminants from the surface of $\mathrm{A}^{\prime}\left(\mathrm{NO}_{3}\right)_{3} \cdot 9 \mathrm{H}_{2} \mathrm{O}$ crystals. It was omitted from pilot tests. However, one of the production centrifuges is expected to provide a cycle in which wash and spent mother liquors are separate a from the crystalline product. Second, this was a pilot run and involved only a fraction of the volume of feedstock of a normal process run. Minimum liquid levels in the crystallizer limited the fraction of liquor recycled and crystallized. Process recycle of 80 to $90 \%$ of the aluminum is exnected, although this will be limited by the concentrations and solubilities of aluminum fluoride con plexes. Thus, the pilot provides a minimum estimate of both produci purity and recycle levt's lilsoly in full scale operation.

Concentrations of aluminum and of oiher inorganic cations were determined using inductively coupled plasma (ICP) spectromeiry. Fluoride was determined using hexamethyldisiloxane distillation, followed by analysis using a fluoride sensitive electrode. Detailed methods are provided in Appendix 2. All of the analytical results are reported in $\mathrm{mg} / \mathrm{kg}$ process solution Appendix 1, Tables $\mathrm{A}_{\mathbf{1}} 1$-A7. To permit evaluation of the relative importance of various impurities, their concentrations have been plotted uniformly on semilog scales as a fraction of elemental aluminum concentration. On these plots, the separation factors for the various trace elements can be estimated from the distances between the feed and product or mother liquor curves. Separation factors at the end of the process run have been tabulated for selected elements. At the limit of the solubility of the aluminum fluoride complexes, good ability to remove the other nitrates of contaminating elements is expected. In this process the'e is no need for complete removal of any of the contaminating elements. There is only a need for the discharge in the mother liquor of a major fraction of the cations feed to the system and the fluoride complex of aluminum.

Aluminum. Aluminum concentrations in feedstock, mother liquor, and product are shown in Table 3.1. As might be expected, the concentration of aluminum is lowest in the feedstock, with concentrations rising in the mother liquor and in the product. Calcium and magnesium are the major cationic contaminants. The tradeoffs in precipitation of these nitrates are shown in Fig. 3.1. This phase diagram illustrates the potential problems in managing high aluminum nitrate recycle levels in an aluminum nitrate - calcium nitrate aluminum nitrate - water system at $25^{\circ} \mathrm{C}$. The purity of aluminum nitrate remains fairly high across a substantial composition range in which it is the predominant cation. Near $40 \%$ calcium nitrate in the mother liçuor, the invariant point, $E$, there is a brief composition range in which mixed aluminum - calcium nitrates are precipitated. At higher calcium concentrations, a nearly pure calcum nitrate is crystallized. Magnesium nitrates are expected to have similar behavior. Minor contamination of aluminum nitrate with 
Table 3.1. Al, $\mathrm{mg} / \mathrm{kg}$, in process streams

\begin{tabular}{rccc}
\hline Day & Feed & iviviher liquor & Product \\
\hline 0 & 19,000 & & \\
7 & 18,000 & 46,000 & \\
9 & 24,000 & 52,000 & \\
11 & 26,000 & 50,000 & \\
12 & 23,000 & 49,000 & 62,000 \\
15 & 34,000 & 51,000 & 63,000 \\
\hline
\end{tabular}

ORNL-OWG 91Z-13330

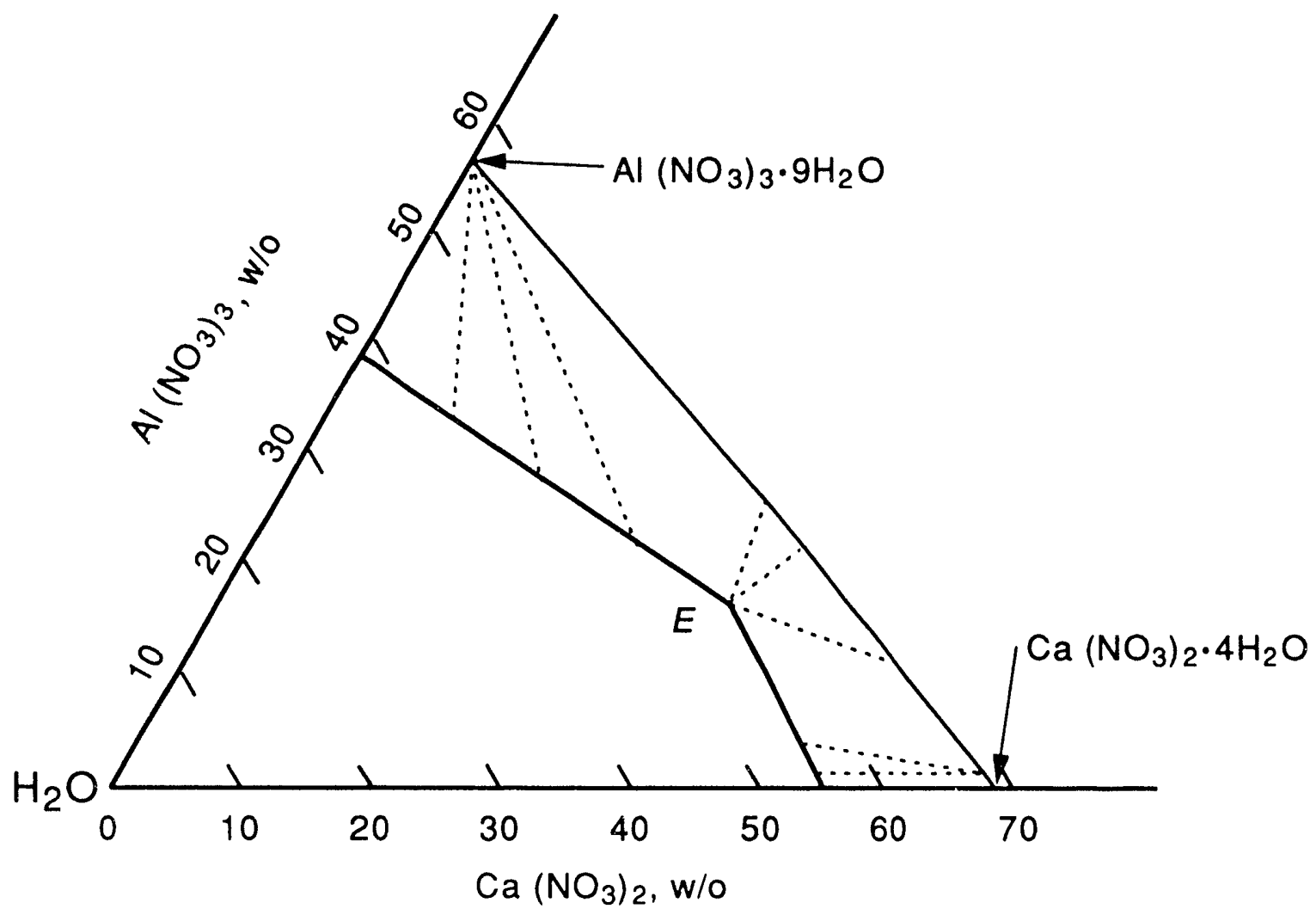

Fig. 3.1. Phase diagram for the system $\mathrm{Al}\left(\mathrm{NO}_{3}\right)_{3}: \mathrm{Ca}\left(\mathrm{NO}_{3}\right)_{2}: \mathrm{H}_{2} \mathrm{O}$ at $25^{\circ} \mathrm{C}$. Source: Nurlieev and coworkers, 1983. 
calcium and magnesium nitrates would not be a problem for the intended use of the crystals. The other nitrates should be reduced to a small fraction of the aluminum to impurity ratio in the feed for a successful process. Again, all of the contaminating nitrates do not have to be removed.

Antimony. The concentrations of antimony in feedstock and in spent mother liquor are shown in Fig. 3.2a. Antimony in the product stream was below the levels of instrumental detectability at the dilutions testad.

Barium. Barium concentration in all three streams is less than $0.1 \%$ of aluminum concentration, as shown in Fig. 3.2b. Barium concentration in the product stream is over an order of magnitude less than that of either the feed stream or the spent mother liquor stream. However, barium concentration does rise with increasing recycle in the absence of sulfate.

Beryllium. Beryllium concentration in the product stream was not plotted in Fig. 3.2c as it was below the limits of detectability. At the highest levels found, concentration of beryllium is less than 10 parts in one million of aluminum.

Boron. Boron concentration in raffinate feedstock and in spent mother liquor are shown in Fig. 3.2d. Boron in the crystallized product was below the ICP analytical threshold, a drop of more than an order of magnitude from that of the feedstock or the spent mother liquor.

Cadmium. Cadmium concentration in the product tank was below the limit of instrumental detection, a factor if two to ten below feedstock and spent liquor concentrations. As shown in Fig. 3.2e, cadmium generally remained less than $0.01 \%$ of the aluminum concentration in feedstock and spent mother liquor.

Calcium. Unlike barium, calcium and magnesium concentrations in the aluminum nitrate recycle streams are substantial. As shown in Fig. 3.2f, calcium concentrations in feedstock and spent mother liquor reached nearly $10 \%$ of aluminum concentration by the end of the pilot run. Product calcium concentration, however, was approximately $0.2 \%$ of aluminum concentration.

Cobalt. As shown in Fig. 3.3a, product cobalt concentrations remained below the limit of instrumental detection for all but the last sample taken in the pilot run. Cobalt concentrations in the feedstock and spent mother liquor, like cadmium, reached approximately $0.01 \%$ of aluminum.

Chromium. Chromium concentrations relative to aluminum are approximately halved by crystallization, as shown in Fig. 3.3b. Chromium is among the highest product trace elements. Although this may be improved by washing crystals in the centrifugation step, monitoring of chromium concentration is likely to be necessary to achieve desired product purity.

Copper. Copper concentrations relative to aluminum are shown in Fig. 3.3c. Copper in the product stream, which ranged between 0.01 and $0.1 \%$ of aluminum, is reduced more than an order of magnitude over feedstock and spent mother liquors.

Fluoride. Although fluoride concentration is of concern it appears to be controlled by crystallization and by distillation in the evaporator. By the end of the run, the feedstock concentration was reduced to approximately $0.1 \%$ of aluminum, as shown in Fig. 3.3d, although the feedstock and spent mother liquor were approximately an order of magnitude higher. 


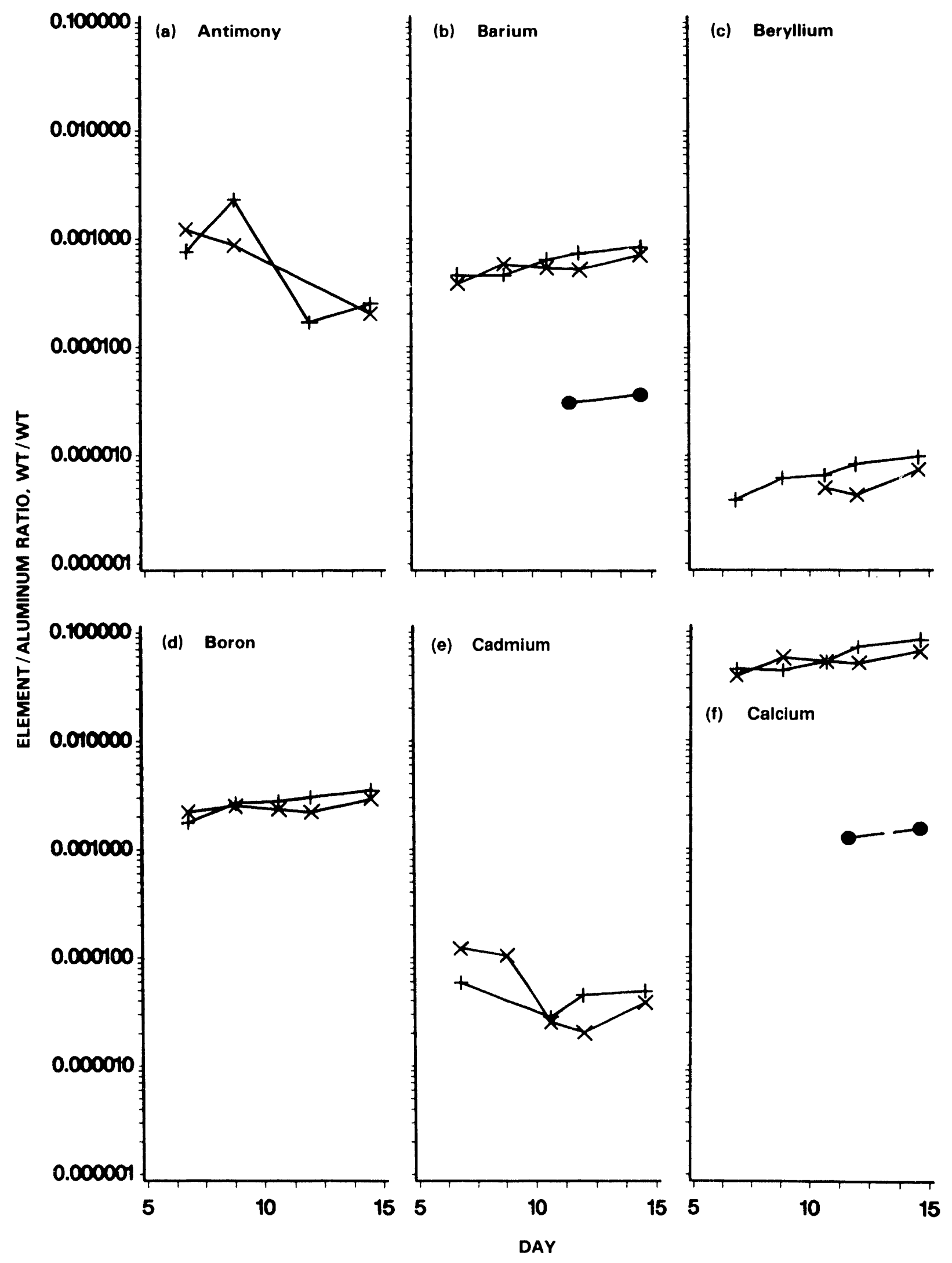

Fig. 3.2. Ratios of (a) antimony, (b) barium, (c) beryllium, (d) boron, (e) calcium, and $(f)$ cadmium to aluminum in feedstock $(X)$, mother liquor $(+)$, and product $(\bullet)$ streams, wt/wt. 


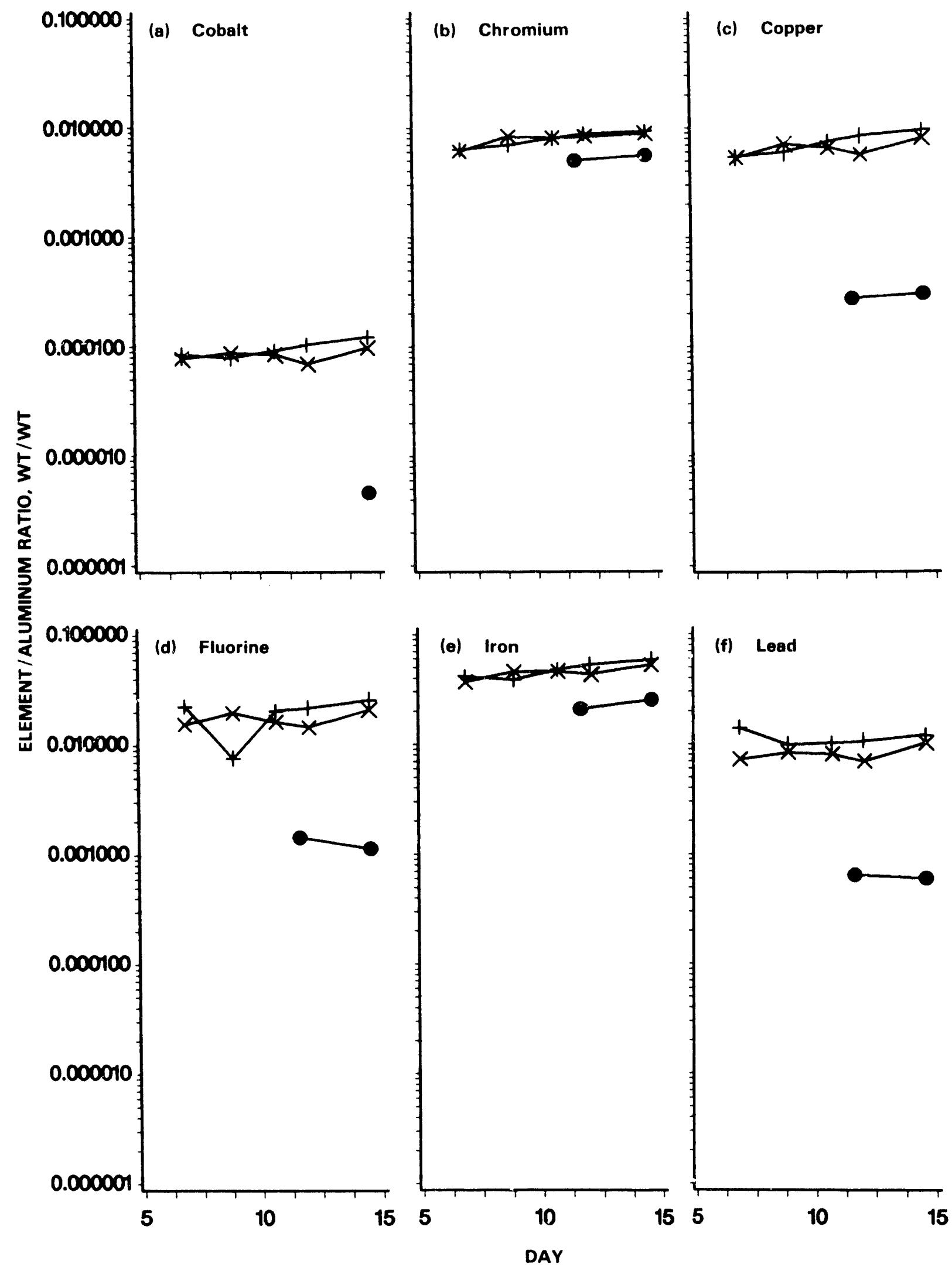

Fig. 3.3. Ratios of (a) cobalt, (b) chromium, (c) copper, (d) fluoride, (e) iron, and $(f)$ lead to aluminum in feedstock $(X)$, mother liquor $(+)$, and product $(\bullet)$ streams, wt/wt. 
Iron. As with chromium, iron concentrations are halved by crystallization. However, all iron concentrations are above $1 \%$ of aluminum, as shown in Fig. 3.3e. Based on earlier bench experiments, washing aluminum crystals in the centrifuge is likely to reduce product iron concentrations. However, monitoring of iron concentrations will probably be needed to achieve desired product purity.

Lead. As shown in Fig. 3.3f, the substantial reductions in lead effected by crystallization reduced product concentrations to well less than $0.1 \%$ of aluminum from the approximately $1 \%$ found in feed and spent mother liquor streams.

Magnesium. Magnesium concentrations are shown in Fig. 3.4a. Product concentrations, which remain below $0.1 \%$ of aluminum, are reduced more than an order of magnitude over those of the feed and spent mother liquor.

Manganese. Manganese concentrations in the product stream, as shown in Fig. 3.4b, is slightly above $10 \mathrm{ppm}$ relative to aluminum. Feed and spent mother liquor streams had manganese concentrations approximately one-thousandth that of aluminum.

Nickel. Although nickel concentrations in the feed and spent mother liquor, as shown in Fig 3.4c, rose to nearly $1 \%$ of aluminum. However, product concentration was nearly thirty times lower, staying well below one part per thousand in the product.

Phosphorous. Only the spent mother liquor concentrations of phosphorous are shown in Fig. 3.4d. Phosphorous concentrations were below the level of instrumental detectability in both the product and the feedstock streams at the dilutions tested. In general, phosphorous values were near or below one part per thousand of aluminum.

Sodium. Although sodium concentrations in the feed and spent mother liquor streams remained between 1 and $10 \%$ of aluminum as shown in Fig. 3.4e. Product concentrations remained substantially lower and are not plotted because they were reported below the limits of instrumental analysis at the dilutions used.

Strontium. Feed and spent mother liquor concentrations of strontium are shown in Fig. 3.4f. Product strontium concentrations were at least ten times lower than the feed and spent mother liquor concentrations: only one point was above the limits of detectability at dilutions tested.

Titanium. Titanium concentrations in the feed and spent mother liquor, as shown in Fig. 3.5a, are below one part in a thousand of aluminum. Product concentrations, below the limits of instrumental detectability at the dilutions tested, were substantially lower.

Vanadium. The concentrations of vanadium in the product stream were below the limits of instrumental detectability at the dilutions tested, and substantially below levels in feed and spent mother liquor shown.

Zinc. Fig. 3.5b shows the concentrations of zinc in all three process streams. The product stream is more than an order of magnitude below that of the feed and spent mother liquor streams, slightly above one ten-thousandth of the aluminum concentration.

Zirconium. Zirconium concentrations, shown in Fig. 3.5c, are a major concern in aluminum stresms. Although the concentration in feed and spent mother liquor streams approached one-thousandth of aluminum by the end of the pilot run, the concentration in product was approximately an order of magnitude lower.

Other elements. A number of other elements occurred at levels which were below the limits of instrumental detectability at the dilutions tested. Concentrations of silver, arsenic, 


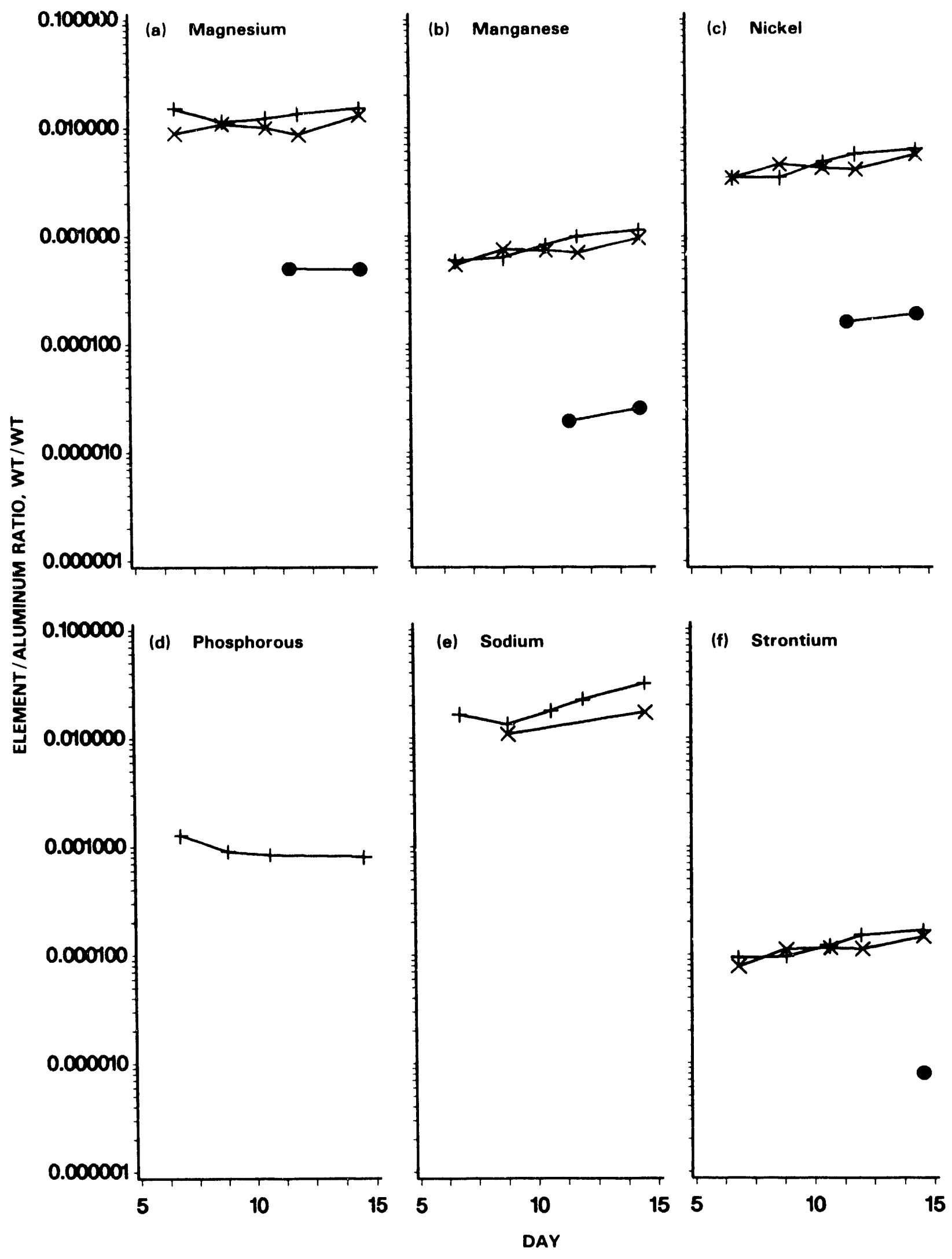

Fig. 3.4. Ratios of (a) magnesium, (b) manganese, (c) nickel, (d) phosphorous, (e) sodium, and (f) strontium to aluminum in feedstock $(X)$, mother liquor $(+)$, and product $(\bullet)$ streams, wt/wt. 

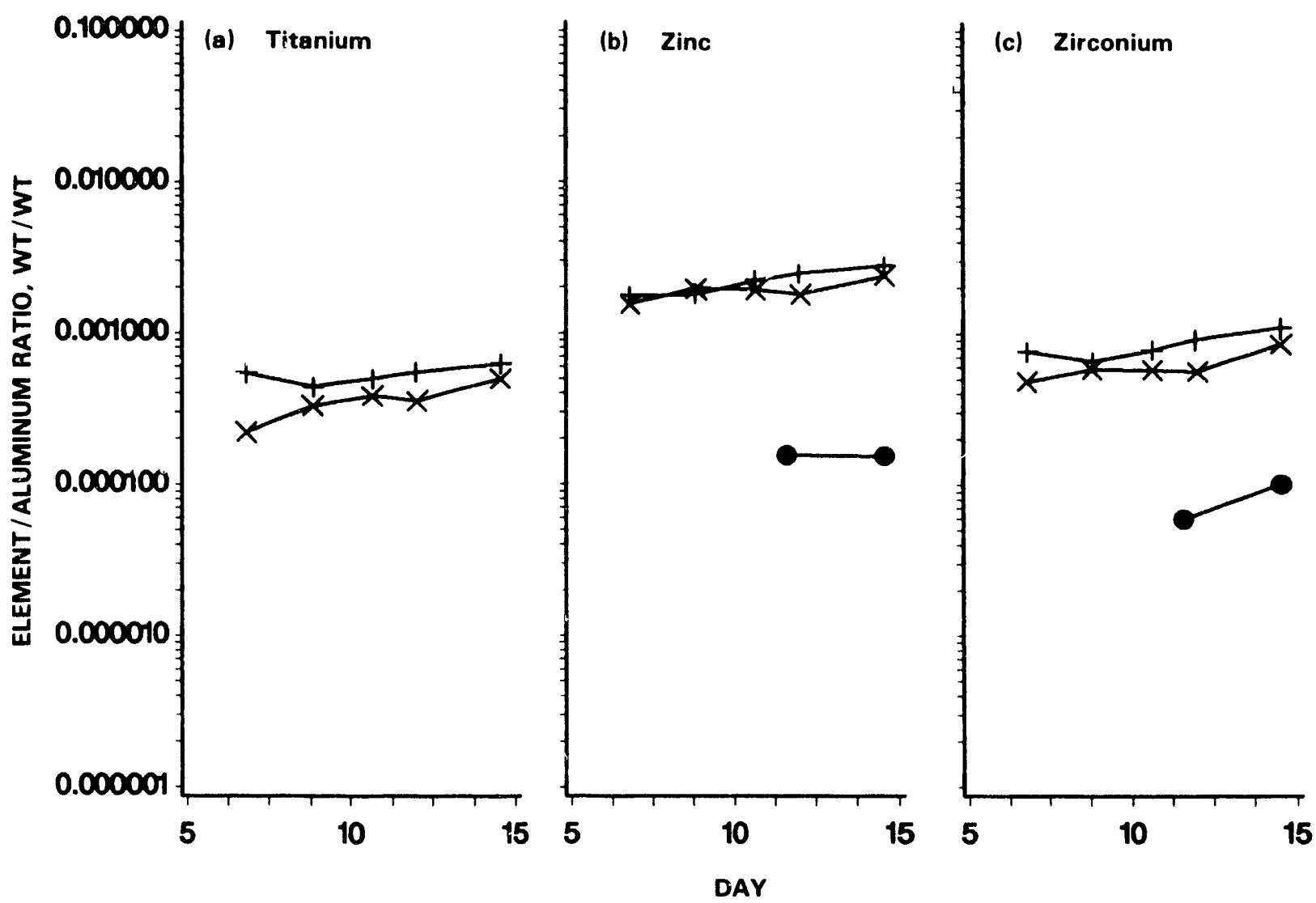

Fig. 3.5. Ratios of (a) titanium, (b) zinc, and (c) zirconium, to aluminum in feedstock $(X)$, mother liquor $(+)$, and product $(\bullet)$ streams, wt/wt

molybdenum, selenium, and tin were near or below $100 \mathrm{ppm}$ of aluminum in the feed, spent mother liquor, and product streams. Silicon concentrations were also below the limits of instrumental detectability, although the minimum values were somewhat higher. However, sample silicon levels could be increased by dissolution of silicon from glass equipment, sample containers, and the mantle of the inductively coupled plasma. Lithium concentrations were also below the limits of instrumental detectability at the dilutions sampled. However, the limits of detectability ranged between 1,000 to $2,000 \mathrm{mg} / \mathrm{kg}$ as lithium. Lithium behavior is similar to that of sodium, giving an expectation of substantially lower values in the product than in the feed or spent mother liquors.

Separation factors. Separation factors for the removal of selected trace elements are presented in Table 3.2. The values calculated reflect the conditions on the last day of the campaign. As discussed above, valence two elements had separations factors ranging between 15 and 50, indicating a low rate of accumulation in the product even at high recycle levels. Valence three cations, including iron and chromium, have separations factors around 2 and may be expected to rise to several times their 1989 (35\% aluminum recycle) level. The question of the best solution to the problem of valence three cation separation hinges 
Table 3.2. Trace element separation factors

\begin{tabular}{lrr}
\hline Element & Feed/product & Mother liquor/product \\
\hline $\mathrm{Ba}$ & 19.3 & 23.1 \\
$\mathrm{Ca}$ & 43.5 & 55.5 \\
$\mathrm{Co}$ & 21.1 & 26.4 \\
$\mathrm{Cr}$ & 1.6 & 1.7 \\
$\mathrm{Cu}$ & 26.3 & 31.2 \\
$\mathrm{~F}$ & 18.3 & 22.4 \\
$\mathrm{Fe}$ & 2.1 & 2.3 \\
$\mathrm{Mg}$ & 26.3 & 30.7 \\
$\mathrm{Mn}$ & 37.1 & 44.0 \\
$\mathrm{Ni}$ & 29.3 & 32.9 \\
$\mathrm{~Pb}$ & 17.1 & 20.2 \\
$\mathrm{Sr}$ & 18.2 & 20.8 \\
$\mathrm{Zn}$ & 15.4 & 18.0 \\
$\mathrm{Zr}$ & 8.4 & 10.8 \\
\hline
\end{tabular}

on its cause. If these materials are being retained in intragranular liquids, crystal washing in the centrifuge should improve the separation factors considerably. However, since some valence three materials are probably coprecipitating with the aluminum in the nitrate crystals themselves, an effective control method may be to insure that the amount of these materials in the mother liquor and crystals is monitored to ensure that the concentration of these materials relative to aluminum does not materially rise on crystallization. Long term buildup can be controlled by selective discarding of a portion of the spent liquor and all centrifuge wash solution. A more complete discussion of control strategies follows in Chapter 4.

Tank precipitates. A sample of precipitates from a feedstock tank was analyzed for trace elements. Silicon and zirconium were the predominant species, although there were measurable concentrations of chromium, titanium, iron, aluminum, and hafnium. Based on earlier research, it is probable that these metals were precipitated as oxalates or fluorides (Ardary and Shappert 1984). Simple filtration prior to evaporation should provide effective control of these materials. Long-term strategies for control of these materials are explored more fully in Chapter 4. 


\section{Discussion and Recommendations}

Based on this pilot test, high levels $(>70 \%)$ of aluminum recycle with acceptable product purity appear possible. These objectives have been achieved without jeopardizing process continuity or requiring extensive capital investment. With attention to product quality, reduction in spent mother liquor sent to the biodenitrification process may be possible. Potential savings have been reported separately, but include decreased aluminum and nitrate costs, decreased operation of biodenitrification processes (including process carbon source), and decreased personnel requirements. However, increased recycle will bring with it a need for increased attention to product quality due to the potential for accumulation of impurities. Process mass balances will be used as a background for elucidation of process advantages and problems.

Aluminum mass balance. The single cycle pilot mass balance for aluminum is shown in Table 4.1. The process shows little loss, and the mass balance closes within analytical error.

Fluorine. Fluorine is the impurity of most concern. As shown in Fig. 4.1, increased fluoride concentrations in mother and evaporator liquors are reflected in increased crystal concentrations. However, there is more than an order of magnitude difference between liquid and crystal concentrations. Even at the figure's 3,000 ppm total fluoride levels, a level which substantially exceeds current and projected operating conditions, it would be possible to increase aluminum nitrate recycle to $75 \%$ if sufficient aluminum ion concentration is maintained. Fluorine is complexed with aluminum to prevent the formation of free fluoride ions which would cause excessive corrosion of stainless steel and glass process equipment. Aluminum, by complexing fluoride, also serves to to prevent sparingly soluble fluorides, such as calcium fluoride, and insoluble fluorides, such as rare earth fluorides, from precipitating. As shown in Fig. 4.2, fluoride to aluminum ratios greater than one on a molar basis ( 0.7 on a elemental weight basis) would be cause for concern. To minimize equipment corrosion, fluoride to aluminum ratios are generally held below one-half of these levels. Generally, as

Table 4.1. Process mass balance based on $1000 \mathrm{~kg}$ of aluminum in feed

\begin{tabular}{lrrrr}
\hline Liquor & $\begin{array}{c}\text { Starting } \\
\text { volume, gal }\end{array}$ & \multicolumn{1}{c}{$\begin{array}{c}\mathrm{Al}, \\
\mathrm{kg}\end{array}$} & $\begin{array}{c}\text { Ending } \\
\text { volume, gal }\end{array}$ & $\begin{array}{c}\mathrm{A} \text { (1, } \\
\mathrm{kg}\end{array}$ \\
\hline Feed solution & 9,569 & 797 & 1,238 & 199 \\
Spent mother liquor & 0 & 0 & 825 & 226 \\
Crystallizer & 803 & 196 & 803 & 227 \\
Evaporator & 68 & 7 & 68 & 12 \\
Product & 0 & 0 & 974 & 338 \\
Total & & 1,000 & & 1,002 \\
\hline
\end{tabular}




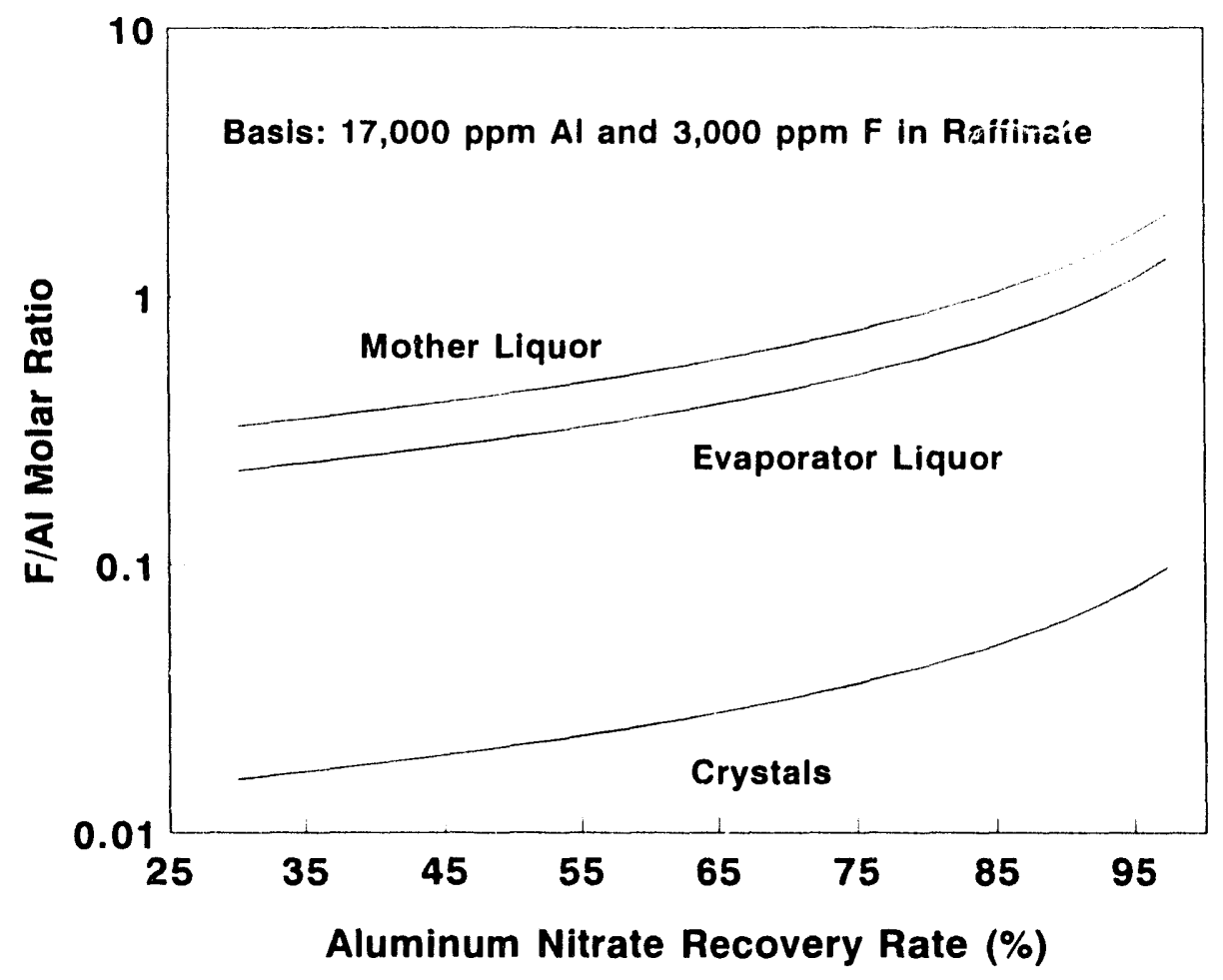

Fig. 4.1. Fluoride ion concentration as a function of $\mathrm{AlF}_{3} / \mathrm{Al}\left(\mathrm{NO}_{3}\right)_{3}$ ratio.

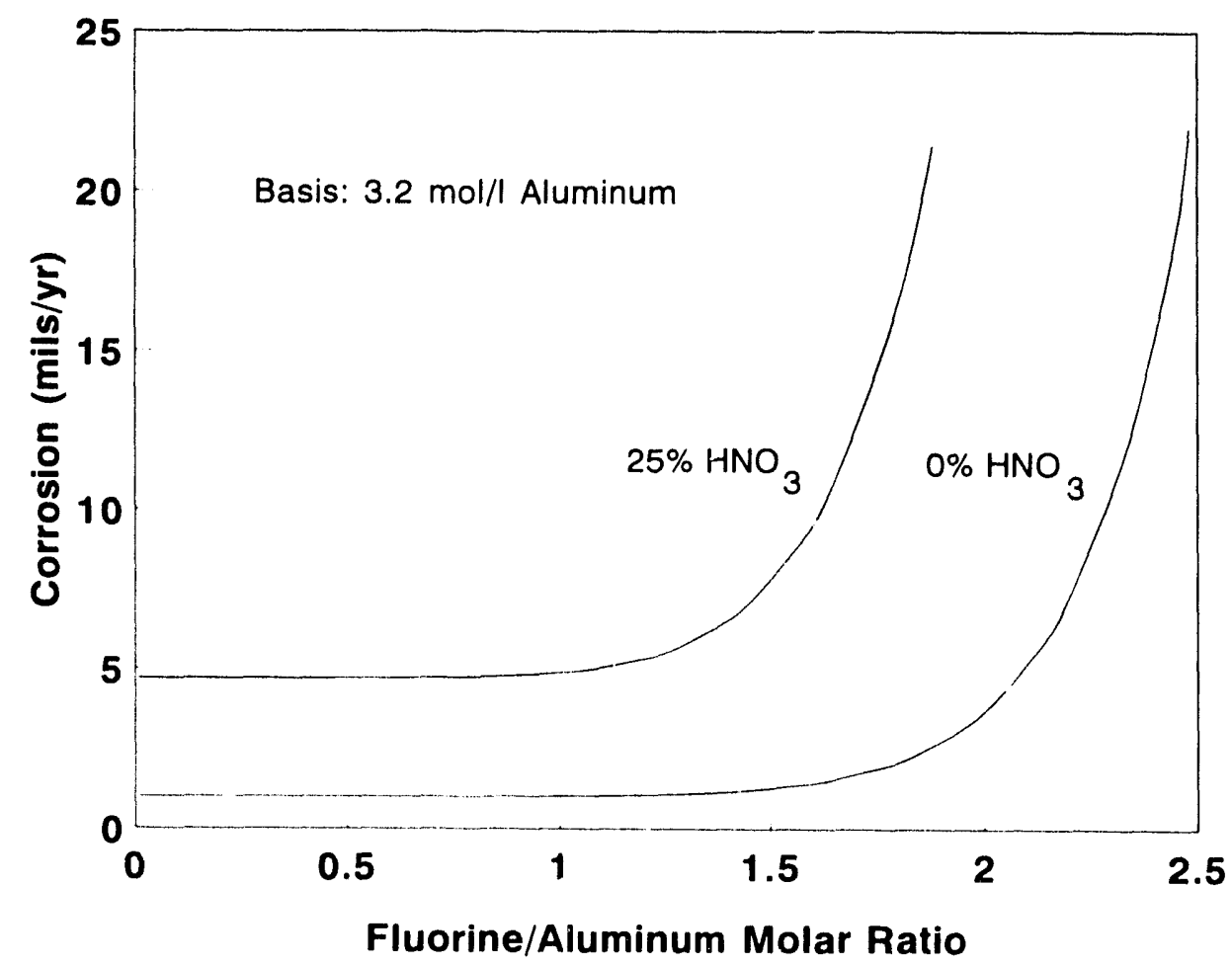

Fig. 4.2. Stainless steel corrosion rate as a function of A1/F molar ratio. 
noted in Chapter 3, product fluorine is at least an order of magnitude below that of either the spent mother liquor or the feedstock. Free fluoride can be decreased by washing product aluminum nitrate crystals in the centrifuge and separating the wash solution.

A fluozine mass balance should be developed. Samples for fluorine determination should be routinely taken to ensure that unacceptable levels of free fluorine do not accumulate. If necessary, fluorine levels could form a basis for discontinuing recycle or for the establishment of discard levels. A relatively simple and inexpensive low temperature method for fluorine determination has been developed (Taves 1968). An adaptation of this method developed at ORNL by Cyrus Feldman and suitable for routine use is given in Appendix 2.

Elements with the potential for long-term buildup. As discussed in Chapter 3, little buildup of valence one and two cations was expected or encountered. Separation factors for valence three cations, however, indicate the possibility of buildup in process streams. Chromium and iron are of the most concern as their presence can be due to cocrystallization with $\mathrm{Al}\left(\mathrm{NO}_{3}\right)_{3} \cdot 9 \mathrm{H}_{2} \mathrm{O}$, as opposed to sorption on the crystal surface or intercrystalline entrapment. Crystal washing in the centrifuge with separation of wash waters can decrease the concentration of surface sorbed and entrapped materials but would be expected to have little effect on a cocrystallized material. Use of a color comparator or a color standard could provide an indication of iron or ch=omium increases. Any highly colored liquors or product, as well as routine process samples, should be analyzed for iron and chromium.

Valence four cations, including zirconium and silicon, showed a mild increase with time. Although pilot concentrations provided limited basis for concern and substantial unexpected increases in zirconium or silicon are not likely, the potential for serious process disturbances makes it prudent to include their analyses in normal process analyses.

Strategies for process control and waste minimization. From the above discussions it should be concluded that the objective is not a chemically pure aluminum nitrate for recycle. The objective is maximum reduction of mother liquor discharge within the limitations of tolerance of the solvent extraction system. As a whole, these interdependent systems can tolerate higher concentrations of the impurities than are now present. In the past, these systems have been successfully operated using copper and iron, rather than aluminum, nitrates. Iron nitrate complexes both sulfate and fluoride to the advantage of the extraction process. Process impurity tolerance could be increased if the pure uranium end of the purification cascade is adequately refluxed. The level of impurities at which the system shows evidence of failure should be established by an evolutionary operating statistics (EVOPS) plan. This will permit continued production while reducing the amounts of nitrate discharged. 


\section{References}

Ardary, Z. L., and S. E. Shappert. 1984. Primary aqueous product cleanup. Y-12 Plant report Y/DZ-106.

Arnold, D. S., and F. J. Podlipec. 1956. Nitric acid recovery from raffinate by evaporation and fractional distillation. Chemical Engineering Progress 52(9): 362-366.

Buslaev, Y. A., and S. P. Petrosyants. 1979. Composition of fluoro complexes of aluminum and fluorosilicic acid in aqueous solutions. Koordinatsionnaya Khimi 5(2): 163-170. (English translation)

Danilova, A. G.; Abdullaeva, A. B.; and Ismatov, Kh. R. 1981. Conditions of the evaporation and crystallization of aluminum nitrate nonahydrate from nitric acid solutions in the presence of alkali metals. VINITI deposited document 3311-81.

Degnan, T. F. 1986. Materials of construction for hydrofluoric acid and hydrogen fluoride. In Process industries corrosion, ed. B. J. Moniz and W. I. Poliock, p. 326. Houston: National Association of Corrosion Engineers.

Dietrich, W. C. 1973. Recovery of nitric acid from raffinate and condensate solutions by steam distillation/pyrohydroiysis and fractional distillation in a glass column. Y-12 Plant report Y-1886.

Efimov, A. N.; Zhikharev, M. I.; and Zhirnov, Y. P. 1963. On the influence of nitrates on the composition of the vapor phase on nitric acid solutions. In Treatment and storage of high-level radioactive wastes, pp. 133-139. U. S. Atomic Energy Commission translation AEC-tr-6269.

Godfrey, W. L. 1964. counter-current crystallization. Hanford Atomic Products Operation report RL-SA-9.

Godfrey, W. L., and R. D. Benham. 1964. Recovery of aluminum nitrate nonahydrate from redox acid waste. Part 1: computer study. U. S. Atomic Energy Commission report HW-82771 PT1.

Johnson, R. V. 1973. Crystallization of aluminum nitrate for Union Carbide Corporation Nuclear Division, Oak Ridge, Tennessee. Struthers Technical Services Laboratory report on pilot project 1.73-17-10288.

Laggis, E. G. 1974a. An operational guide to the Y-12 nitrate recycle facility. Y-12 Plant report Y-DA-6094.

Laggis, E. G. 1974b. Pilot plant nitric acid recovery by distillation of condensate waste. Y-12 Plant report Y-1950.

Matwiyoff, N. A., and W. E. Wageman. 1970. Nuclear magnetic resonance studies of aluminum (III) fluoride ion complexes in aqueous solutions. Inorganic Chemistry 9(5): 1031-1036.

Mesmer, R. E., and A. C. Rutenberg. 1973. Fluorine-19 nuclear magnetic resonance studies on fluoroborate species in aqueous solution. Inorganic Chemistry 12(3): 699-702.

Miniovich, M. A.; Shneerson, A. L.; Chernyshev, A. K.; Filippova, Zh. M.; Miniovich, V. M.; and Soroko, S. N. 1975. Solubility of magnesium nitrate and some of its mixtures with calcium nitrate in 40, 50, and $60 \%$ nitric acid. Zhurnal Prikladnoi Khimii 48(4): 878-880. (English translation)

Nurkeev, S. S.; Sabitov, A. R.; Romanov, L. G.; and Shakirova, G. D. 1983. Study of solubility in the aluminum nitrate-calcium nitrate-nitric acid-water system at $25^{\circ} \mathrm{C}$. Kompleksn. Ispol'z. Miner. Syr'ya (3): 55-59. (English translation) 
Patton, F. S.; Googin, J. M.; and Griffith, W. L. 1963. Enriched uranium processing. New York: Pergamon Press.

Saslawsky, Von A. J., and J. L. Ettinger. 1935. Gemeinsame loslichkeit der aluminum-, natrium-, kalium-, und eisennitrate im wasser in gegenwart von salpetersaure. Mitteilung I. Zeitschrift fur Anorganische und Allgemeine Chemie 223: 277-287.

Saslawsky, Von A. J.; Ettinger, J. L.; and Eserowa, E. A. 1935. Gemeinsame loslichkeit der aluminum-, natrium-, kalium-, und eisennitrate im wasser in gegenwart von salpetersaure. Mitteilung I. Zeitschrift fur 3_3 Anorganische und Allgemeine Chemie 225(4): 305-311.

Shakhova, A. F.; Friedman, S. G.; and Tseitlin, M. A. 1979. Concentration of nitric acid solutions of nitrates. Vopr. Khim. Tekhnol. 55: 84-88.

Struthers Scientific and International Corporation. 1974. Operating instructions, forced circulation evaporator and contact cooling crystallizer of $\mathrm{Al}\left(\mathrm{NO}_{3}\right)_{3} \cdot 9 \mathrm{H}_{2} \mathrm{O}$, Union Carbide P. O. 81 Y54434V.. Report 9-74-05-10369.

Takeshi, S.; Ichiro, H.; Toshikatsu, H.; and Hiroshi, Y. 1985. Salt effects O. $_{\text {.- }}$ por-liquid equilibrium for $\mathrm{HNO}_{3}-\mathrm{H}_{2} \mathrm{O}$ system. Kagaku Kogaku Rambun. Shu. Kagaku Kogaku Ronhunshu. 11(3): $267-\therefore, 68$.

Tannanaev, I. V., and A. D. Vinogradova. 1957. The composition and stability of some aluminum fluorides in solution. Zhurnal Neorganicheskoi Khimii 2(10): 2455-2467.

Taves, D. R. 1968. Separation of fluoride by rapid diffusion using hexamethyldisiloxane. Talanta 15: $969-974$.

Turner, T. L., and D. T. Rogers. 1983. Aluminum miniplant operations - evaporative crystallization of aluminum nitrate nonahydrate from aluminum nitrate solutions. U. S. Department of the Interior Bureau of Mines report 8830.

Union Carbide Corporation - Nuclear Division. 1974. Title 1 design report for acid waste neutralization and recycle facility. Y-12 Plant report Y-EC-309.

Vasil'ev, V. P., and E. V. Kozlouskii. 1975. Thermodynamic characteristics of processes for the formation of aluminum and cadmium fluorocomplexes in aqueous solution. Zhurnal Neorganicheskoi Khimii 20: 1196-1199.

Yamazaki, M., and T. Takeuchi. 1967. High resolution nuclear magnetic resonance studies of the aluminum fluoride complexes. Kogyo Kaguku Zasshi 70(5) 656-665. 


\section{Appendix 1. Analytical Results}

Tables providing the concentrations of inorganic cations in samples of process solutions follow. The ccncentrations, in $\mathrm{mg} / \mathrm{kg}$ solution, form the basis for the results presented in Chapter 3 tables.

Table A1. Inorganic elements, $\mathrm{mg} / \mathrm{kg}$, in Tank F621 during pilot run

\begin{tabular}{|c|c|c|c|c|c|c|}
\hline Element & Day 1 & Day 6 & Day 8 & Day 10 & Day 11 & Day 14 \\
\hline $\mathrm{Ag}$ & $<0.50$ & $<0.56$ & $<0.54$ & $<0.56$ & $<0.51$ & $<0.65$ \\
\hline $\mathrm{Al}$ & 19,000 & 18,000 & 24,000 & 26,000 & 23,000 & $34, \mathrm{C} 00$ \\
\hline As & $<5.0$ & $<5.6$ & $<5.4$ & $<5.6$ & $<5.1$ & $<6.5$ \\
\hline B & 56 & 40 & 61 & 61 & 51 & 100 \\
\hline $\mathrm{Ba}$ & 7.0 & 6.9 & 14 & 14 & 12 & 24 \\
\hline $\mathrm{Be}$ & $<0.04$ & $<0.04$ & $<0.04$ & 0.13 & 0.10 & 0.25 \\
\hline $\mathrm{Ca}$ & 690 & 710 & 1,400 & 1,400 & 1,200 & 2,300 \\
\hline $\mathrm{Cd}$ & 2.3 & 2.2 & 2.5 & 0.66 & 0.47 & 1.3 \\
\hline Co & 1.8 & 1.4 & 2.1 & 2.2 & 1.6 & 3.3 \\
\hline $\mathrm{Cr}$ & 130 & 110 & 200 & 210 & 190 & 300 \\
\hline $\mathrm{Cu}$ & 130 & 95 & 170 & 170 & 130 & 270 \\
\hline F & 153 & 280 & 476 & 424 & 338 & 710 \\
\hline $\mathrm{Fe}$ & 730 & 660 & 1,100 & 1,200 & 1,000 & 1,800 \\
\hline $\mathrm{Li}$ & $<1,500$ & $<1,700$ & $<1,600$ & $<1,700$ & $<1,500$ & $<2,000$ \\
\hline $\mathrm{Mg}$ & 120 & 160 & 260 & 260 & 200 & 440 \\
\hline $\mathrm{Mn}$ & 11 & 9.7 & 18 & 19 & 16 & 32 \\
\hline Mo & $<4.0$ & $<4.5$ & $<4.3$ & $<4.4$ & $<4.1$ & $<5.2$ \\
\hline $\mathrm{Na}$ & 230 & $<220$ & 260 & $<220$ & $<200$ & 580 \\
\hline $\mathrm{Ni}$ & 65 & 62 & 110 & 110 & 95 & 190 \\
\hline $\mathrm{P}$ & $<30$ & $<34$ & $<32$ & $<33$ & $<31$ & $<39$ \\
\hline $\mathrm{Pb}$ & 67 & 130 & 200 & 210 & 160 & 350 \\
\hline $\mathrm{Sb}$ & 20 & 22 & 21 & $<1.4$ & $<4.1$ & 7.0 \\
\hline $\mathrm{Se}$ & $<8.0$ & $<8.9$ & $<8.6$ & $<8.9$ & $<8.2$ & $<10$ \\
\hline $\mathrm{Si}$ & $<20$ & $<22$ & $<22$ & $<22$ & $<20$ & $<26$ \\
\hline $\mathrm{Sn}$ & $<5.0$ & $<5.6$ & $<5.4$ & $<5.6$ & $<5.1$ & $<6.5$ \\
\hline $\mathrm{Sr}$ & 1.4 & 1.4 & 2.7 & 3.0 & 2.6 & 5.0 \\
\hline $\mathrm{Ti}$ & 3.4 & 4.0 & 7.9 & 10 & 8.2 & 17 \\
\hline V & 11.1 & 0.89 & 0.60 & 1.6 & 1.3 & 2.3 \\
\hline $\mathrm{Zn}$ & 33 & 28 & 47 & 50 & 41 & 80 \\
\hline $\mathrm{Zr}$ & 8.6 & 8.7 & 14 & 15 & 13 & 29 \\
\hline
\end{tabular}


Table A2. Inorganic elements, $\mathrm{mg} / \mathrm{kg}$, in Tank F624 during pilot run

\begin{tabular}{|c|c|c|c|c|c|c|}
\hline Element & Day 1 & Day 6 & Day 8 & Day 10 & Day 11 & Day 14 \\
\hline $\mathrm{Ag}$ & $<0.49$ & $<0.61$ & $<0.50$ & $<0.60$ & $<0.57$ & $<0.56$ \\
\hline $\mathrm{Al}$ & 46,000 & 47,000 & 52,000 & 55,000 & 53,000 & 53,000 \\
\hline As & $<4.9$ & $<6.1$ & $<5.0$ & $<6.0$ & $<5.7$ & $<5.6$ \\
\hline B & 72 & 90 & 140 & 150 & 160 & 170 \\
\hline $\mathrm{Ba}$ & 20 & 20 & 31 & 35 & 38 & 40 \\
\hline $\mathrm{Be}$ & 0.17 & 0.15 & 0.40 & 0.40 & 0.44 & $0.4 \delta$ \\
\hline $\mathrm{Ca}$ & 2,000 & 1,900 & 3,000 & 3,500 & 3,900 & 4,100 \\
\hline $\mathrm{Cd}$ & 2.3 & 2.6 & 1.9 & 1.5 & 2.2 & 2.4 \\
\hline Co & 3.8 & 3.9 & 4.8 & 4.9 & 5.5 & 5.6 \\
\hline $\mathrm{Cr}$ & 280 & 310 & 400 & 460 & 470 & 470 \\
\hline $\mathrm{Cu}$ & 230 & 250 & 390 & 400 & 430 & 460 \\
\hline $\mathrm{F}$ & 1,014 & 692 & 1,037 & 948 & 1,070 & 1,306 \\
\hline $\mathrm{Fe}$ & 1,700 & 1,900 & 2,500 & 2,800 & 2,900 & 3,000 \\
\hline $\mathrm{Li}$ & $<1,500$ & $<1,800$ & $<1,500$ & $<1,800$ & $<1,700$ & $<1,700$ \\
\hline $\mathrm{Mg}$ & 730 & 540 & 650 & 630 & 680 & 740 \\
\hline $\mathrm{Mn}$ & 25 & 26 & 41 & 46 & 50 & 54 \\
\hline Mo & $<3.9$ & $<4.9$ & $<4.0$ & $<4.8$ & 4.7 & 5.9 \\
\hline $\mathrm{Na}$ & 670 & 600 & 1,100 & 1,100 & 1,300 & 1,500 \\
\hline $\mathrm{Ni}$ & 160 & 150 & 240 & 270 & 290 & 310 \\
\hline $\mathbf{P}$ & 50 & 58 & 51 & 44 & 44 & 38 \\
\hline $\mathrm{Pb}$ & 690 & 460 & 550 & 500 & 560 & 590 \\
\hline $\mathrm{Sb}$ & 41 & 34 & 4.7 & 9.9 & 7.7 & 8.9 \\
\hline $\mathrm{Se}$ & $<7.8$ & $<9.8$ & $<8.0$ & $<9.6$ & $<9.1$ & $<9.0$ \\
\hline $\mathrm{Si}$ & $<20$ & $<25$ & $<20$ & $<24$ & $<23$ & $<23$ \\
\hline $\mathrm{Sn}$ & $<4.9$ & $<6.1$ & $<5.0$ & $<6.0$ & $<5.7$ & $<5.6$ \\
\hline $\mathrm{Sr}$ & 4.2 & 4.0 & 6.0 & 7.0 & 7.7 & 8.2 \\
\hline $\mathrm{Ti}$ & 19 & 21 & 26 & 25 & 28 & 29 \\
\hline V & 1.8 & 2.7 & 2.8 & 3.5 & 3.7 & 3.9 \\
\hline $\mathrm{Zn}$ & 78 & 76 & 110 & 120 & 130 & 140 \\
\hline $\mathrm{Zr}$ & 31 & 29 & 38 & 42 & 51 & 53 \\
\hline
\end{tabular}


Table A3. Inorganic elements, $\mathrm{mg} / \mathrm{kg}$, in Tank F624A during pilot run

\begin{tabular}{|c|c|c|c|c|c|}
\hline Element & Day 1 & Day 6 & Day 8 & Day 10 & Day 11 \\
\hline $\mathrm{Ag}$ & $<0.53$ & $<0.54$ & $<0.55$ & $<0.54$ & $<0.54$ \\
\hline $\mathrm{Al}$ & 35,600 & 52,000 & 59,000 & 58,000 & 60,000 \\
\hline As & $<5.3$ & $<5.4$ & $<5.5$ & $<5.4$ & 5.8 \\
\hline B & 97 & 120 & 130 & 140 & 180 \\
\hline $\mathrm{Ba}$ & 13 & 19 & 32 & 35 & 44 \\
\hline $\mathrm{Be}$ & 0.09 & 0.19 & 0.34 & 0.40 & 0.52 \\
\hline $\mathrm{Ca}$ & 1,300 & 1,900 & 2,500 & 3,600 & 4,600 \\
\hline $\mathrm{Cd}$ & 2.7 & 2.8 & 1.3 & 1.9 & 2.6 \\
\hline Co & 2.6 & 3.6 & 4.2 & 4.8 & 6.4 \\
\hline $\mathrm{Cr}$ & 250 & 360 & 470 & 500 & 540 \\
\hline $\mathrm{Cu}$ & 220 & 290 & 350 & 390 & 510 \\
\hline $\mathrm{F}$ & 294 & 437 & 831 & 957 & 1,276 \\
\hline $\mathrm{Fe}$ & 1,700 & 2,000 & 2,700 & 2,900 & 3,300 \\
\hline $\mathrm{Li}$ & $<1,600$ & $<1,600$ & $<1,700$ & $<1,600$ & $<1,600$ \\
\hline $\mathrm{Mg}$ & 230 & 370 & 490 & 600 & 810 \\
\hline $\mathrm{Mn}$ & 20 & 30 & 39 & 46 & 59 \\
\hline Mo & $<4.3$ & $<4.3$ & $<4.4$ & $<4.3$ & 6.8 \\
\hline $\mathrm{Na}$ & 460 & 970 & 970 & 1,200 & 1,600 \\
\hline $\mathrm{Ni}$ & 110 & 170 & 230 & 270 & 340 \\
\hline $\mathrm{P}$ & 38 & 55 & 38 & 35 & 42 \\
\hline $\mathrm{Pb}$ & 130 & 200 & 380 & 490 & 640 \\
\hline $\mathrm{Sb}$ & 30 & 40 & 18 & 4.9 & 4.7 \\
\hline $\mathrm{Se}$ & $<8.5$ & $<8.7$ & $<8.8$ & $<8.6$ & $<8.7$ \\
\hline $\mathrm{Si}$ & $<21$ & $<22$ & $<22$ & $<22$ & 22 \\
\hline $\mathrm{Sn}$ & $<5.3$ & $<5.4$ & $<5.5$ & $<5.4$ & $<5.4$ \\
\hline $\mathrm{Sr}$ & 2.6 & 4.1 & 5.7 & 7.1 & 8.8 \\
\hline $\mathrm{Ti}$ & 42 & 11 & 19 & 25 & 32 \\
\hline V & 7.4 & 2.0 & 2.8 & 3.7 & 4.3 \\
\hline $\mathrm{Zn}$ & 56 & 79 & 100 & 120 & 150 \\
\hline $\mathrm{Zr}$ & 17 & 19 & 30 & 41 & 56 \\
\hline
\end{tabular}


Table A4. Inorganic elements, $\mathrm{mg} / \mathrm{kg}$, in Tank F624F during pilot run

\begin{tabular}{|c|c|c|c|}
\hline Element & Day 8 & Day 10 & Day 11 \\
\hline $\mathrm{Ag}$ & $<0.52$ & $<0.62$ & $<0.51$ \\
\hline $\mathrm{Al}$ & 51,000 & 51,000 & 53,000 \\
\hline As & $<5.3$ & $<6.2$ & $<5.1$ \\
\hline B & 150 & 140 & 160 \\
\hline $\mathrm{Ba}$ & 28 & 34 & 38 \\
\hline $\mathrm{Be}$ & 0.35 & 0.39 & 0.45 \\
\hline $\mathrm{Ca}$ & 2,400 & 3,000 & 3,900 \\
\hline $\mathrm{Cd}$ & 0.93 & 1.9 & 2.2 \\
\hline Co & 4.4 & 5.0 & 5.4 \\
\hline $\mathrm{Cr}$ & 380 & 440 & 460 \\
\hline $\mathrm{Cu}$ & 340 & 390 & 430 \\
\hline$F$ & 1,028 & 1,122 & 1,238 \\
\hline $\mathrm{Fe}$ & 2,200 & 2,600 & 2,900 \\
\hline $\mathrm{Li}$ & $<1,600$ & $<1,900$ & $<1,500$ \\
\hline $\mathrm{Mg}$ & 610 & 620 & 690 \\
\hline $\mathrm{Mn}$ & 36 & 44 & 51 \\
\hline Mo & $<4.2$ & $<4.9$ & 5.4 \\
\hline $\mathrm{Na}$ & 930 & 1,000 & 1,500 \\
\hline $\mathrm{Ni}$ & 210 & 260 & 290 \\
\hline$P$ & 40 & $<37$ & 44 \\
\hline $\mathrm{Pb}$ & 510 & 500 & 560 \\
\hline $\mathrm{Sb}$ & 140 & 7.3 & 9.6 \\
\hline $\mathrm{Se}$ & $<8.4$ & $<9.9$ & $<8.2$ \\
\hline $\mathrm{Si}$ & $<21$ & $<25$ & $<21$ \\
\hline Sn & $<5.3$ & $<6.2$ & $<5.1$ \\
\hline $\mathrm{Sr}$ & 5.3 & 6.7 & 7.6 \\
\hline $\mathrm{Ti}$ & 24 & 25 & 29 \\
\hline V & 2.5 & 3.1 & 4.1 \\
\hline $\mathrm{Zn}$ & 100 & 110 & 130 \\
\hline $\mathrm{Zr}$ & 35 & 40 & 50 \\
\hline
\end{tabular}


Table A5. Inorganic elements, $\mathrm{mg} / \mathrm{kg}$, in Tank F630 during pilot run

\begin{tabular}{|c|c|c|c|c|c|}
\hline Element & Day 6 & Day 8 & Day 10 & Day 11 & Day 14 \\
\hline $\mathrm{Ag}$ & $<0.55$ & $<0.59$ & $<0.63$ & $<0.64$ & $<0.56$ \\
\hline $\mathrm{Al}$ & 46,000 & 52,000 & 50,000 & 49,000 & 51,000 \\
\hline As & $<5.5$ & $<5.9$ & $<6.4$ & $<6.4$ & $<5.6$ \\
\hline B & 81 & 140 & 140 & 150 & 180 \\
\hline $\mathrm{Ba}$ & 21 & 24 & 32 & 36 & 43 \\
\hline $\mathrm{Be}$ & 0.18 & 0.32 & 0.33 & 0.41 & 0.50 \\
\hline $\mathrm{Ca}$ & 2,100 & 2,300 & 2,700 & 3,600 & 4,400 \\
\hline $\mathrm{Cd}$ & 2.7 & $<0.24$ & 1.4 & 2.2 & 2.5 \\
\hline Co & 3.9 & 4.1 & 4.6 & 5.1 & 6.2 \\
\hline $\mathrm{Cr}$ & 290 & 360 & 400 & 430 & 470 \\
\hline $\mathrm{Cu}$ & 250 & 310 & 370 & 410 & 480 \\
\hline$F$ & 1,045 & 395 & 1,039 & 1,070 & 1,303 \\
\hline $\mathrm{Fe}$ & 1,900 & 2,000 & 2,400 & 2,600 & 3,000 \\
\hline $\mathrm{Li}$ & $<1,600$ & $<1,800$ & $<1,900$ & $<1,900$ & $<1,700$ \\
\hline $\mathrm{Mg}$ & 690 & 590 & 610 & 660 & 770 \\
\hline $\mathrm{Mn}$ & 27 & 33 & 41 & 48 & 57 \\
\hline Mo & $<4.4$ & $<4.7$ & $<5.1$ & $<5.1$ & 6.3 \\
\hline $\mathrm{Na}$ & 750 & 690 & 890 & 1,100 & 1,600 \\
\hline $\mathrm{Ni}$ & 160 & 180 & 240 & 280 & 320 \\
\hline $\mathrm{P}$ & 59 & 47 & 42 & $<38$ & 41 \\
\hline $\mathrm{Pb}$ & 640 & 510 & 510 & 520 & 620 \\
\hline $\mathrm{Sb}$ & 35 & 120 & $<5.1$ & 8.4 & 13 \\
\hline $\mathrm{Se}$ & $<8.7$ & $<9.5$ & $<10$ & $<10$ & $<8.9$ \\
\hline $\mathrm{Si}$ & $<22$ & $<24$ & $<25$ & $<26$ & $<22$ \\
\hline $\mathrm{Sn}$ & $<5.5$ & $<5.9$ & $<6.4$ & $<6.4$ & $<5.6$ \\
\hline $\mathrm{Sr}$ & 4.3 & 5.0 & 6.1 & 7.4 & 8.6 \\
\hline $\mathrm{Ti}$ & 25 & 23 & 25 & 27 & 32 \\
\hline $\mathrm{V}$ & 2.4 & 2.3 & 3.2 & 3.6 & 4.2 \\
\hline $\mathrm{Zn}$ & 80 & 93 & 110 & 120 & 140 \\
\hline $\mathrm{Zr}$ & 35 & 34 & 39 & 45 & 56 \\
\hline
\end{tabular}


Table A6. Inorganic elements, $\mathrm{mg} / \mathrm{kg}$, in Tank $\mathrm{C632}$ during pilot run

\begin{tabular}{|c|c|c|c|c|}
\hline Element & Day 6 & Day 8 & Day 10 & Day 11 \\
\hline $\mathbf{A g}$ & $<0.67$ & $<0.53$ & $<0.53$ & $<0.63$ \\
\hline $\mathrm{Al}$ & 110 & 60 & 14 & $<6.4$ \\
\hline As & $<6.7$ & $<5.3$ & $<5.3$ & $<6.4$ \\
\hline B & $<11$ & $<8.5$ & $<8.5$ & $<10$ \\
\hline $\mathrm{Ba}$ & $<0.27$ & $<0.21$ & $<0.21$ & $<0.25$ \\
\hline $\mathrm{Be}$ & $<0.05$ & $<0.04$ & $<0.04$ & $<0.05$ \\
\hline $\mathrm{Ca}$ & $<6.7$ & $<5.3$ & $<5.3$ & $<6.4$ \\
\hline $\mathrm{Cd}$ & 2.2 & 1.5 & $<0.21$ & $<0.25$ \\
\hline Co & $<0.40$ & $<0.32$ & $<0.32$ & $<0.38$ \\
\hline $\mathrm{Cr}$ & $<0.40$ & $<0.32$ & $<0.32$ & $<0.38$ \\
\hline $\mathrm{Cu}$ & $<1.1$ & $<0.85$ & $<0.85$ & $<1.0$ \\
\hline $\mathrm{F}$ & 21 & 46 & 24 & 49 \\
\hline $\mathrm{Fe}$ & 7.0 & 5.3 & 5.2 & 1.6 \\
\hline $\mathrm{Li}$ & $<2,000$ & $<1,600$ & $<1,600$ & $<1,900$ \\
\hline $\mathbf{M g}$ & $<1.3$ & 1.8 & 1.4 & $<1.3$ \\
\hline $\mathrm{Mn}$ & $<0.27$ & $<0.21$ & $<0.21$ & $<0.25$ \\
\hline Mo & $<5.3$ & $<4.2$ & $<4.3$ & $<5.1$ \\
\hline $\mathrm{Na}$ & $<270$ & $<210$ & $<210$ & $<250$ \\
\hline $\mathrm{Ni}$ & 8.8 & 6.2 & $<0.64$ & $<0.76$ \\
\hline $\mathrm{P}$ & $<40$ & $<32$ & $<32$ & $<38$ \\
\hline $\mathrm{Pb}$ & $<4.0$ & $<3.2$ & $<3.2$ & $<3.8$ \\
\hline $\mathrm{Sb}$ & 27 & 18 & $<4.3$ & $<5.1$ \\
\hline $\mathrm{Se}$ & $<11$ & $<8.5$ & $<8.5$ & $<10$ \\
\hline $\mathrm{Si}$ & $<27$ & $<21$ & $<21$ & $<25$ \\
\hline $\mathrm{Sn}$ & $<6.7$ & $<5.3$ & $<5.3$ & $<6.4$ \\
\hline $\mathrm{Sr}$ & $<0.67$ & $<0.53$ & $<0.53$ & $<0.63$ \\
\hline $\mathrm{Ti}$ & $<2.7$ & $<2.1$ & $<2.1$ & $<2.5$ \\
\hline $\mathrm{V}$ & 0.42 & 0.56 & $<0.32$ & $<0.38$ \\
\hline $\mathrm{Zn}$ & 0.75 & $<0.53$ & 0.64 & $<0.63$ \\
\hline $\mathrm{Zr}$ & $<2.7$ & $<2.1$ & $<2.1$ & $<2.5$ \\
\hline
\end{tabular}


Table A7. Inorganic elements, $\mathrm{mg} / \mathbf{k g}$, in Tank F637 during pilot run

\begin{tabular}{|c|c|c|}
\hline Element & Day 11 & Day 14 \\
\hline $\mathrm{Ag}$ & $<0.58$ & $<0.47$ \\
\hline $\mathrm{Al}$ & 62,000 & 63,000 \\
\hline As & $<5.8$ & $<4.7$ \\
\hline B & $<9.3$ & $<7.6$ \\
\hline $\mathrm{Ba}$ & 1.9 & 2.3 \\
\hline $\mathrm{Be}$ & $<0.05$ & $<0.04$ \\
\hline $\mathrm{Ca}$ & 79 & 98 \\
\hline $\mathrm{Cd}$ & $<0.23$ & $<0.19$ \\
\hline Co & $<0.35$ & 0.29 \\
\hline $\mathrm{Cr}$ & 310 & 350 \\
\hline $\mathrm{Cu}$ & 17 & 19 \\
\hline $\mathbf{F}$ & 90 & 72 \\
\hline $\mathrm{Fe}$ & 1,300 & 1,600 \\
\hline $\mathrm{Li}$ & $<1,800$ & $<1,400$ \\
\hline $\mathbf{M g}$ & 31 & 31 \\
\hline $\mathrm{Mn}$ & 1.2 & 1.6 \\
\hline Mo & $<4.7$ & $<3.8$ \\
\hline $\mathrm{Na}$ & $<230$ & $<190$ \\
\hline $\mathrm{Ni}$ & 10 & 12 \\
\hline $\mathbf{P}$ & $<35$ & $<28$ \\
\hline $\mathrm{Pb}$ & 40 & 38 \\
\hline $\mathrm{Sb}$ & $<4.7$ & $<3.8$ \\
\hline $\mathrm{Se}$ & $<9.3$ & $<7.6$ \\
\hline $\mathrm{Si}$ & $<23$ & $<19$ \\
\hline $\mathrm{Sn}$ & $<5.8$ & $<4.7$ \\
\hline $\mathrm{Sr}$ & $<0.58$ & 0.51 \\
\hline $\mathrm{Ti}$ & $<2.3$ & $<1.9$ \\
\hline V & $<0.35$ & $<0.28$ \\
\hline $\mathrm{Zn}$ & 9.6 & 9.6 \\
\hline $\mathrm{Zr}$ & 3.7 & 6.4 \\
\hline
\end{tabular}




\section{Appendix 2. Materials and Methods}

Density. Direct readings of liquid sample density were made using a standard hydrometer at $25^{\circ} \mathrm{C}$. Two phase samples were heated and agitated to dissolve crystalline precipitates. They were then cooled to $25^{\circ} \mathrm{C}$ and slowly poured into a hydrometer jar. Density readings were taken promptly before crystal development occurred.

Fluoride determination. Sample fluoride determinations were made by Cyrus Feldman of the ORNL Analytical Chemistry Division using a method similar to that of Taves (1968). In this method, hexamethyldisiloxane was used as a catalytic carrier which transfers fluoride ion from the sample solution to an alkaline trap solution in which it can be measured using a fluoride sensitive electrode. Although the method was developed for measuring fluoride concentrations in tungsten alloys, it was applicable in a wide variety of fluoride analyses. A brief summary of the method was provided below.

Fifty $\mathrm{ml}$ or less of sample was transferred to a wide-mouthed plastic jar and $10 \mathrm{ml}$ of a $2: 1 \mathrm{v} / \mathrm{v}$ of concentrated $\mathrm{HClO}_{4}$ and $\mathrm{H}_{3} \mathrm{PO}_{4}$ was added. Approximately $2 \mathrm{ml}$ of a $1 \%$ hexamethyldisiloxane solution in $6 \mathrm{~N} \mathrm{HCl}$ was added and the mixture was swirled to mix. An uncapped $28 \mathrm{ml}$ polystyrene vial containing $8.5 \mathrm{ml}$ of $0.1 \mathrm{~N} \mathrm{NaOH}$ was placed in the plastic jar. After the jar was tightly capped, it was incubated in a $60^{\circ} \mathrm{C}$ oven for $24 \mathrm{hr}$. The $\mathrm{NaOH}$ trapping solution was removed and brought to a volume of $10 \mathrm{ml}$ with distilled water. Then $1 \mathrm{ml}$ of total ionic strength adjusting (TISAB III) buffer was added, the sample decanted into an appropriate container, and the fluoride concentration measured using an Orion fluoride sensitive electrode.

Inductively coupled plasma spectroanalyzer. The concentrations of inorganic ions, other than fluorine, were determined using the JY 48 inductively coupled plasma (ICP) spectroanalyzer. Liquid samples were aspirated, nebulized, and formed into a plasma by inductively coupled radio frequency generator. Individual elements were determined by sorption of element-specific light frequencies by individual-element photomultipliers. Concentrations were calculated by a computer using calibration curves for each elementphotomultiplier set.

The ICP technique is extremely efficient, since many elements can be determined simultaneously in a single, small sample. However, the technique suffers from the large amount of information which must be obtained from a single sample dilution. The instrument is capable of detecting extremely low concentrations of given elements under carefully controlled conditions; however, low elemental values are generally reported as being below a given threshold. In a heterogeneous process sample, the compromises necessary to find an appropriate dilution can result in reports of high lower limit values for some elements, $e$. g., lithium.

It is expected that three techniques will be used to improve this situation with process samples. First, different sample dilutions reflecting concentrations of elements of interest can be run. Second, control samples with high levels of aluminum can be used to prepare calibration curves. Third, both ORNL and Y-12 are replacing the photomultiplier-based ICP units with ICP-quadrupole mass spectrometer units. In theory, this should eliminate some of the bleed and dilution problems, as well as provide a constant lower sample limit at or below one $\mathrm{mg} /$ liter. 


\section{INTERNAL DISTRIBUTION}

1. H. R. Butler, Jr.

2. R. M. Canon

3-7. A. L. Compere

8. J. D. Dillon

9. M. L. Elmore

10. C. P. Frew

11. R. W. Glass

12-16. J. M. Googin

17-21. W. L. Griffith

22. C. A. Hall

23-27. W. P. Huxtable

28. I. W. Jeter

29. J. S. Johnson, Jr.

30. J. A. Kreykes

31. R. N. Lambert

32. L. W. Little
33. E. E. McCullough

34. N. G. McRae

35. B. Niemanr

36. M. D. Ohara

37. F. S. Patton, Jr.

38. G. L. Pfennigwerth

39. T. W. Pickel, Jr.

40. R. C. Riepe

41. Central Research Library

42. K-25 Plant Library

43. ORNL Patent Office

44. Y-12 Technical Library /

Document Reference Station

45. Laboratory Records - RC

46-47. Laboratory Records Department

\section{EXTERNAL DISTRIBUTION}

48-49. OSTI, U.S. Department of Energy, P.O. Box 62, Oak Ridge, TN 37831. 

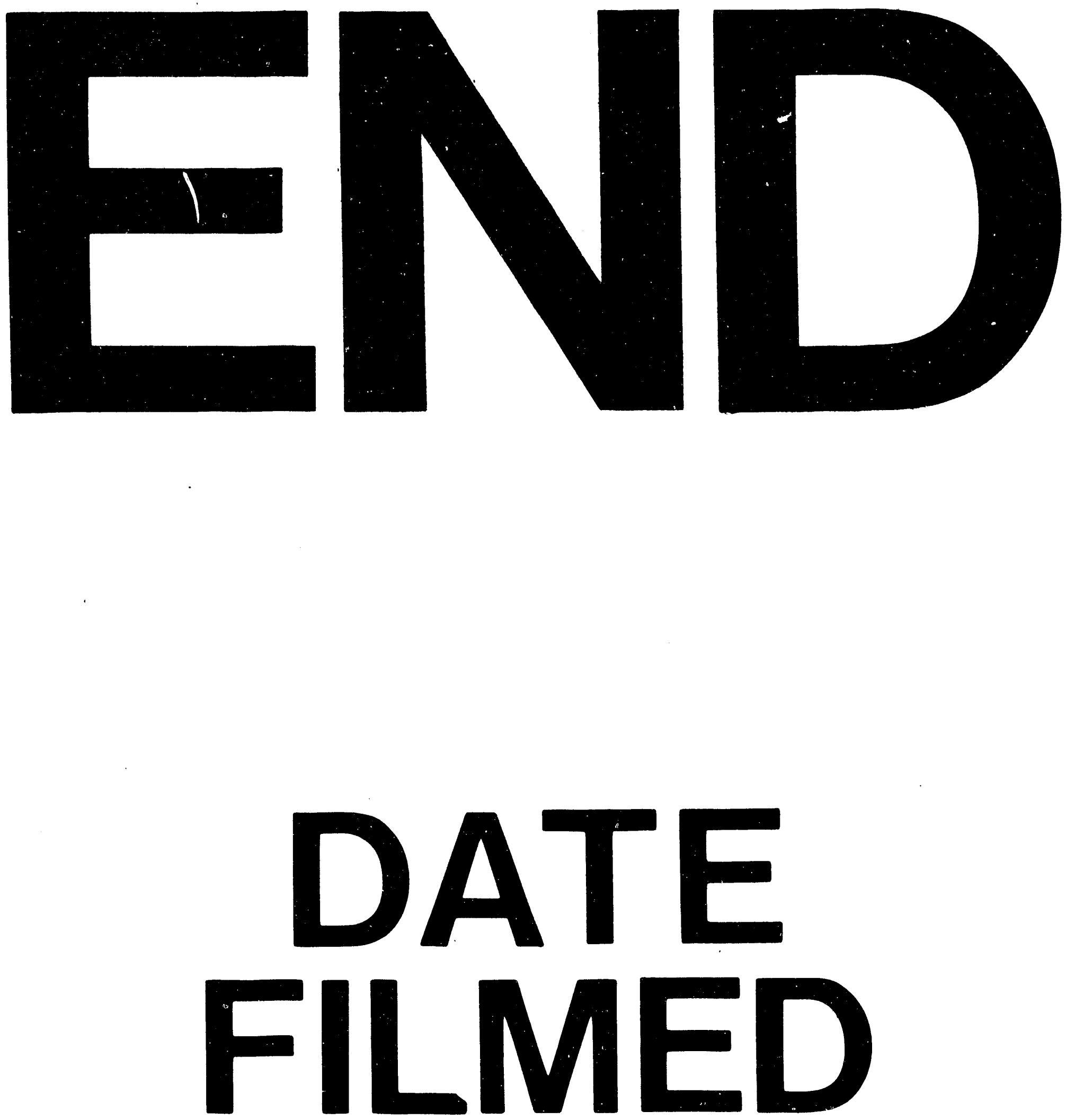

$\theta$

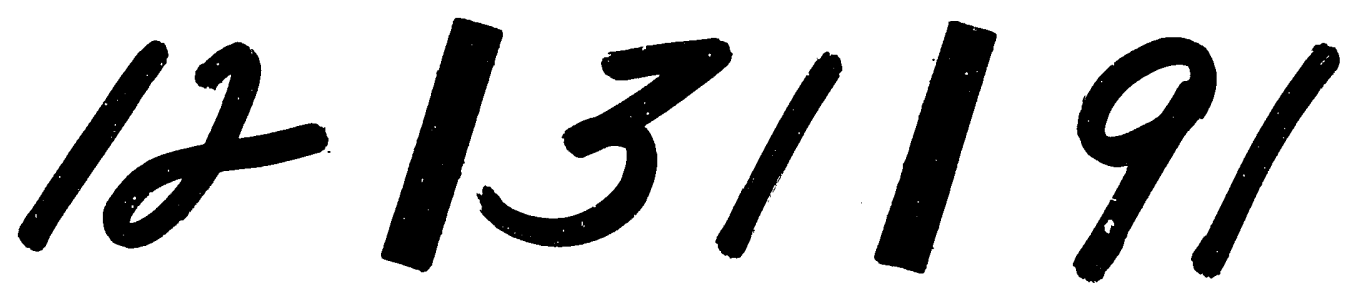


